\title{
EL PAPEL DE LOS ROTHSCHILD EN LA EVOLUCIÓN DE LAS FINANZAS PÚBLICAS ESPAÑOLAS DURANTE EL SIGLO XIX*
}

\author{
MIGUEL A. LÓPEZ-MORELL \\ Universidad de Murcia ${ }^{\mathrm{a}}$
}

\begin{abstract}
RESUMEN
Este trabajo intenta analizar el papel que desempeñaron los capitales movilizados por la Casa de banca Rothschild en la financiación de los gastos del Estado español durante el Siglo XIX. Por lo tanto, se pretende aportar una cronología elemental de las relaciones de la Casa Rothschild con las finanzas públicas españolas durante todo el periodo, analizar las operaciones más significativas, cuantificar su volumen anual agregado y hacer un mínimo acercamiento a las variables coste-beneficio que entraron en juego. Para cubrir estos fines se ha contado con fuentes primarias, localizadas en los archivos de las ramas británica y francesa de los Rothschild, cuyos fondos se han contrastado con los de la Administración francesa y española y de instituciones financieras claves en el periodo, como el Banco de España.

* Parte de este trabajo, que resume algunas de las conclusiones de mi Tesis Doctoral, ha sido discutido como seminario en las universidades Pompeu Fabra, de Sevilla, Murcia, Vigo, del País Vasco y Valencia. Quiero agradecer especialmente las críticas y recomendaciones que mis colegas me hicieron en cada uno de ellos y especialmente las de Albert Carreras, Xavier Tafunell, Lluis Castañeda, Antonio Luis López Martínez, María Teresa Pérez Picazo, Miguel A. Pérez de Perceval, Ángel P. Martínez Soto, Josep María Pons, José M. Martínez Carrión, Mercedes Bernal, Andrés Sánchez Picón, M Á Ángeles Pons y Concha Betrán, así como a los evaluadores anónimos y los miembros de mi tribunal de tesis Pedro Tedde, Antonio Gómez Mendoza, José Luis García Ruiz, José María O’Kean y José Ignacio Martínez Ruiz, y al director del trabajo, Antonio Miguel Bernal. El resultado final y las opiniones que en él se exponen son de mi entera responsabilidad. Agradezco, de igual manera, la financiación que he disfrutado por parte de los programas de becas a la investigación de la Fundación Caja Madrid y del Banco de España.

a Facultad de Economía y Empresa. Campus de Espinardo S/N, 30100, Murcia (Spain)

mlmorell@um.es.
\end{abstract}


Palabras clave: Finanzas públicas, historia financiera, España (hasta 1913), Rothschild, deuda pública

\begin{abstract}
This article attempts to analyse the role that the Rothschild House played in the evolution of Spanish Public Finances along the 19th Century. Therefore, it endeavours to describe an elementary chronology of the relationships between the Spanish Government and the Rothschild House during the whole Century, analysing the main financial operations they underwrote, quantifying their annual aggregate figures and, finally, trying to comment upon the different consequences of the process above mentioned. To cover these aims, we have deployed original records from the Rothschild Archives in London and Paris, their contents having been supplemented with information from National Public Records in Spain and France, and other financial institutions, namely the Bank of Spain.
\end{abstract}

Keywords: Public finances, financial history, Spain (Pre-1913), Rothschild, public debt,

JEL Classification: F34, G15, H81, N13

\title{
1. INTRODUCCIÓN
}

La evolución de las finanzas públicas españolas durante el siglo XIX sigue un camino complejo y tortuoso hacia una normalización siempre relativa. Desde un primer momento el Estado español tuvo que hacer frente a su propia descomposición interna y a la pérdida de las colonias americanas, cuyos metales preciosos habían sufragado durante siglos sus gastos corrientes y la política imperial. En las décadas siguientes, la penuria económica, la estrechez del mercado financiero nacional y los vaivenes en la dirección política fueron agravando el problema, de tal manera que el recurso a préstamos y a emisiones de deuda en malas condiciones constituyeron las vías seguidas por el Tesoro para cubrir sus necesidades más perentorias. A los primeros gobiernos liberales no les quedó otro remedio que acudir a estos ingresos; de ahí el alegato que hizo Santillán (reed. 1960, vol. 1, pp. 154 y 157) en defensa de estas operaciones, caras, pero fundamentales para salvar el cambio político. Sin embargo, la incapacidad de los sucesivos ejecutivos para hacer ajustes y recabar recursos con solvencia obligó a numerosas suspensiones de pagos y «arreglos», que llevaron a los títulos españoles al descrédito y pusieron al Estado en manos de especuladores y oportunistas, dentro y fuera de España.

Las cifras del presupuesto del Estado ponen sobre la mesa algunos de estos desequilibrios. Obsérvese en el Gráfico 1 cómo, dentro de una tendencia general 


\section{GRÁFICO 1}

EVOLUCIÓN DE LOS PRESUPUESTOS DEL ESTADO ESPAÑOL, 1814-1900

(Millones ptas.)

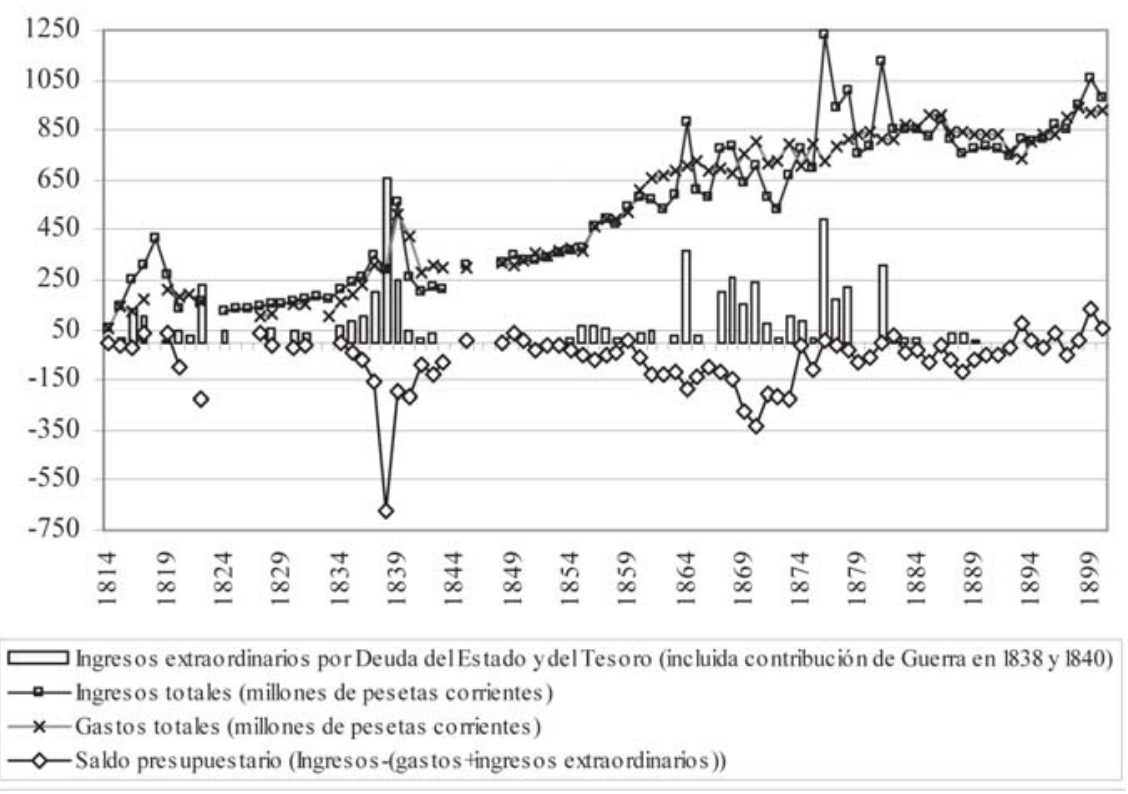

Fuentes: Comín (1989), excepto los ingresos y gastos de 1840, 1843 y 1848 y los ingresos extraordinarios de 1820-1830, 1838, 1840, 1841 y 1842, tomados de Artola (1986, pp. 111, 158, 199 y 256).

Nota: Las liquidaciones presupuestarias oficiales anteriores a 1850 están mal contabilizadas.

al crecimiento, el comportamiento de ingresos y gastos difiere como consecuencia de la incorporación de ingresos extraordinarios por deuda en épocas de crisis. Por consiguiente, se constata que la recaudación de tributos, a pesar de la reforma fiscal de 1845, resultó insuficiente para cubrir las necesidades de la Hacienda, y su discurrir más bien se vinculó a la evolución de la renta. Los gastos estuvieron, por su parte, condicionados por el pago de intereses de esa deuda, que representó entre el 20 y el 60 por cien de los desembolsos. De acuerdo con Tedde (1981), estos porcentajes no fueron mayores que los de otros países de nuestro entorno, pero tienen que matizarse por los continuos impagos y reconversiones que sufrieron los bonos españoles, que repercutieron especialmente en el coste final de la financiación pública. 
Este trabajo intenta analizar la importancia que tomaron los capitales extranjeros en el conjunto de esos ingresos extraordinarios, con especial referencia a aquellos que llegaron a través de la Casa Rothschild. Es importante reseñar que no estamos hablando de una entidad financiera cualquiera, sino posiblemente de la más prestigiosa de la Europa del siglo XIX, que demostró un dominio abrumador en la colocación de empréstitos estatales en las Bolsas de Londres y París ${ }^{1}$, así como en los negocios mercantiles, el descuento de letras, los seguros y el arbitraje de oro y plata. En las finanzas españolas, como en las de otras economías occidentales, los Rothschild desempeñaron un papel muy activo, que fue derivando hacia otros negocios como los ferrocarriles y la minería ${ }^{2}$. Del desarrollo específico de algunos de estos negocios conocemos bastante por los trabajos de Otazu (1987), Gille (1965 y 1967), Ferguson (1998), Martín (1980), Fontana (1977) y Roldán (1997 y 2003), aunque carecemos de una visión de conjunto para todo el siglo. Por consiguiente, este artículo pretende aportar algunos datos sobre sus relaciones con las finanzas públicas españolas durante ese periodo, analizar las operaciones más significativas, cuantificar su volumen anual agregado y llevar a cabo un mínimo acercamiento a las variables coste-beneficio que entraron en juego. Para cubrir estos fines se ha contado con fuentes primarias, localizadas en los archivos de las ramas británica y francesa de los Rothschild, cuyos fondos se han contrastado con los de la Administración francesa y española y de instituciones financieras claves en el periodo, como el Banco de España.

\section{NUEVE MOMENTOS CLAVE PARA ENTENDER LAS RELACIONES DE LOS ROTHSCHILD CON LAS FINANZAS PÚBLICAS ESPAÑOLAS}

\subsection{4: la negativa de Fernando VII}

En 1814 la Corona española se encontraba técnicamente en bancarrota. El Estado reconocía títulos por valor de 12.000 millones de reales, más de diez veces los ingresos anuales de la Hacienda, a pesar de haber aceptado sólo una parte de la deuda generada durante la Guerra de Independencia ${ }^{3}$. A la espera de épocas de mayor bonanza económica, esa deuda se podría haber refinanciado a través de varios empréstitos en Londres, París o Ámsterdam, tal y como estaban haciendo

\footnotetext{
${ }^{1}$ Sólo en Londres, N. M. Rothschild \& Sons emitió bonos por valor de 250 millones de libras desde 1815 a 1859, muy por delante del segundo emisor, Baring, que solo emitió 66 millones. En París, James Rothschild emitió unos 1.100 millones de francos en empréstitos extranjeros entre 1813 y 1830. Vid. Ferguson (1998, pp. 289-290), Chapman (1984, cap. 2), Bouvier (1967 p. 70) y Gille (1965-1967).

2 Véase López-Morell (1999a y 1999b).

3 Vid. Fontana (1973, pp. 99-101) y (1974, p. 381).
} 
otros países cercanos, precisamente de la mano de los Rothschild y otros banqueros. Sin embargo, esta política se descartó de antemano por la renuencia de Fernando VII a acudir al crédito exterior.

Los liberales del Trienio sí que confiaron en las bondades de un endeudamiento contenido en el extranjero para salir de la parálisis de la Administración, y prepararon un programa de empréstitos. Los Rothschild fueron los primeros en ser consultados y llegarían a ofertar un empréstito, pero sus iniciativas se vieron frenadas por la negativa de las Cortes a pagar los intereses de sus emisiones en Londres y por la oposición de Canga Argüelles a cederles la venta del azogue de Almadén en México ${ }^{4}$, fundamental para la obtención de plata de sus minerales. No obstante, los banqueros no cejaron en su intento por hacerse con la tutela financiera de las Cortes hasta el último momento, a pesar de las presiones en contra de Metternich; lo que no fue óbice para que ofrecieran sus servicios para pagar la intervención de los Cien Mil Hijos de San Luis, y que concedieran a Angulema crédito ilimitado durante la campaña ${ }^{5}$. Ésta finalizó inmediatamente después de la liberación del Rey en Cádiz, donde las Cortes se habían refugiado del ejército invasor, y en parte gracias a los 2 millones de francos que Nathan Rothschild remitió para sobornar a algunos parlamentarios liberales ${ }^{6}$.

El círculo parecía haberse cerrado y todo estaba preparado para que los Rothschild se hicieran con el control financiero de la situación, con la anuencia de las potencias europeas en liza ${ }^{7}$. Sin embargo, cualquier iniciativa al respecto chocó con la decisión de Fernando VII de repudiar las deudas emitidas por las Cortes. La medida, aunque se intentara justificar con el argumento de la imposibilidad de hacer frente a la carga de sus intereses, atacaba directamente al crédito de España como nación y la colocaba en una difícil situación de cara al futuro. De hecho, los mercados y la clase financiera de toda Europa reaccionaron inmediatamente y un Committee of Spanish Bondholders, creado al efecto, exigió el cierre de la Bolsa de Londres a cualquier emisión de deuda española ${ }^{8}$.

Ante la necesidad de obtener fondos, Fernando VII y su Ministro Ballesteros volcarían todas sus ofertas en el banquero Alejandro Aguado, que se encargaría

${ }^{4}$ Artola (1986, p. 100), Broder (1981, pp. 371-372), y Cartas de James Rothschild al Gobierno de 12/7/1820, así como su respuesta de 18/9/1820, Archivo Histórico Nacional, Sección Estado, legajos 97 y 5.324

${ }^{5}$ Emitieron para este fin dos empréstitos por 582 millones de francos. Ferguson (1998, pp. 140-141).

${ }^{6}$ Véase Corti (1928, pp. 819-820) y Bouvier (1967, p. 78).

${ }^{7}$ El Primer Ministro francés Villèle prohibió a otros banqueros, como Ouvrard, que iniciaran operaciones con la Regencia frente a los Rothchild. Vid. Gille (1965, Vol. 1, pp. 114-115).

${ }^{8}$ Véanse Fontana (1973, pp. 210-215) y Artola (1986, pp. 148 y 156). París no siguió la medida por su afinidad política con España y también porque, de los 608,5 millones de reales obtenidos por las Cortes, 499,5 lo fueron en Londres y sólo 109 en París. Vid. Broder (1981, p. 403). 
de las emisiones de deuda española en París durante el resto de la «década ominosa» ${ }^{9}$.

\subsection{0: toma de posiciones y primer contrato de Almadén}

La época final del reinado de Fernando VII supuso un giro sustancial en la forma de hacer política en España. Más aún cuando el Rey se empeñó en la defensa de los derechos sucesorios de su hija Isabel frente al Infante don Carlos, que acabó en un acercamiento a los grupos liberales. Desde el exterior, la llegada de Luis Felipe al poder en Francia y del rey liberal don Pedro en el vecino Portugal, apoyado por Mendizábal y Nathan Rothschild ${ }^{10}$, dibujan un nuevo marco en las relaciones diplomáticas en Europa, en el que se ha rebajado claramente la influencia de las monarquías conservadoras.

Los Rothschild reaccionaron rápido a estas señales, y en diciembre de 1830 desarrollaron dos operaciones coincidentes, de las que no tuvo conocimiento el público, que iban a delimitar con claridad las intenciones de la familia con respecto al país.

La primera de ellas estuvo de nuevo vinculada a Almadén, aunque los condicionantes habían cambiado radicalmente desde su última propuesta. Por una parte, la Hacienda venía pasando dificultades para sostener la comercialización desde 1821, pese a la rebaja del precio a 40 pesos del quintal castellano de azogue y a las facilidades que dio el Gobierno mexicano a la entrada de los mercurios españoles ${ }^{11}$. En este estado de cosas, ni tan siquiera se cubrían los gastos de la mina, que en tiempos vendía sus productos a 82,7 pesos $^{12}$. La situación era tan desesperada que el Gobierno decidió arrendar las ventas por subasta. Por otra parte, la familia Rothschild acababa de hacerse con el control del yacimiento austriaco de Idria que, a pesar de producir sólo el equivalente a una cuarta parte del mercurio que producía Almadén, constituía el único factor de competencia para contener los precios, por lo que los incentivos para adjudicarse la concesión eran importantes. Sin embargo, quizá por no querer involucrarse aún con la monarquía española, los Rothschild no se presentaron a la puja, sino que se aprovecharon

\footnotetext{
${ }^{9}$ En total, y según Fontana (1973, p. 272), entre 1824 y 1833 los títulos de Aguado reportarían a la Hacienda Pública 1.773,3 millones de reales líquidos y servirían para amortizar hasta 714,6 millones.

${ }^{10}$ Ambos emitieron un empréstito de 4 millones de libras para la monarquía portuguesa (Contrato de 23/4/1834). Archivos Rothschild Londres (en adelante ARL) XI/4/99 y Janke (1974, pp. 58-59 y 114-116).

${ }^{11}$ Véanse Martín (1980, p. 188) y Randall (1977, p. 186).

12 De acuerdo con Dobado (1997, p. 465), éste era el precio que se había mantenido durante las décadas centrales del siglo XVIII.
} 
de la oferta de Íñigo Ezpeleta, un comerciante de Burdeos que se hizo con el contrato el 23 de marzo de 1830 por 37,25 pesos (745 reales) el quintal. No hay datos que confirmen que Ezpeleta se presentase en nombre de los Rothschild, pero sí que habían llegado en diciembre a un acuerdo para que les cediera parte de los 20.000 quintales anuales del contrato a cambio de una comisión del 2,5 por cien sobre las ventas ${ }^{13}$. Tampoco conocemos la evolución de este convenio en su primer año, pero nos consta que Pérez Ansoategui, un cuñado de Ezpeleta afincado en Cádiz, entregaba a los banqueros toda la producción de Almadén desde $1832^{14}$. Si nos atenemos a la evolución de los precios en México que, de acuerdo con Randall (1977, p. 187), subieron un 60 por cien en un año, es de suponer que los Rothschild ya habían pasado de puros comisionistas a monopolizar el mercado.

Paralelamente a estas operaciones, James Rothschild firmó un acuerdo con Aguado y otros banqueros para elevar el precio de la Deuda de las Cortes del 15 por cien al 30 por cien de su nominal en París, de cara a una conversión de estos títulos ${ }^{15}$. Un mes más tarde Aguado convencía en Madrid a Fernando VII de las bondades de un nuevo empréstito, en el que se canjearía parte de los títulos del Trienio $^{16}$. Los Rothschild no participaron en esta emisión, última de la «década ominosa», aunque los términos del anterior acuerdo demuestran su predisposición a incorporarse a los inminentes cambios en la política española y a las operaciones financieras que se le presumían aparejadas. En cualquier caso, al poco de la muerte de Fernando VII Campbell escribía desde Londres al Banco de San Fernando comentándole sus dificultades para realizar compras en su nombre, ya que Nathan estaba acaparando títulos de deuda española ${ }^{17}$.

\subsection{4-1835: la consolidación de los negocios en España}

Fallecido el Rey, Cea Bermúdez se negó a aceptar más propuestas de Aguado, así como varias que le llegaron de los Rothschild para hacer coincidir un empréstito con el reconocimiento de la Deuda de Cortes. El Tesoro, mientras tanto, volvía a estar sin un real a fines de 1833, con un déficit de 200 millones y unas necesidades previstas a corto plazo cercanas a los 400 millones, que no podría cubrir el Banco de San Fernando, porque hacía meses que bordeaba el límite legal para sus adelantos al Tesoro ${ }^{18}$.

${ }^{13}$ Véanse Gille (1965, p. 414), Sánchez Molero (1859, pp. 29-30), Martín (1980, pp. 187-190) y Ferguson (1998, p. 379).

${ }^{14}$ ARL, XI/38/3-5.

15 Véase Ferguson (1998, p. 379).

16 Véanse Fontana (1973, pp. 260-269) y Fernández Acha (1976, pp. 26-27).

${ }^{17}$ Carta de 20/11/1833, Archivo del Banco de España (ABE en adelante), Secretaría, legajo 1196

${ }^{18}$ Véanse Tedde (1999, pp. 47-48), Gille (1965, pp. 245-247) y Fontana (1977, pp. 43 y 60-61, y 1973, pp. 268-269). 
El nuevo gobierno de Martínez de la Rosa tuvo que hacer frente al inicio de la guerra civil y, antes de que empeorara la situación, envió a Londres al Marqués de Miraflores con el encargo de negociar el apoyo del gobierno británico y conseguir fondos entre los banqueros de la City. Miraflores estuvo en Londres y también en París, donde obtuvo el compromiso de Palmerston y Talleyrand para formar la «Cuádruple Alianza» contra los intentos legitimistas de don Miguel y don Carlos. Se trajo también un acuerdo con los Rothschild, firmado el 7 de junio de 1834, que significaba toda una declaración de principios: por la consecución de un adelanto de 15 millones de francos, el Gobierno español se obligaba a presentar una ley que reconociera los empréstitos de las Cortes «sobre las bases más equitativas y favorables»; por otra parte, incorporaba una cláusula de exclusividad bancaria para los Rothschild y prohibía gestionar cualquier operación hasta no haberles devuelto su adelanto. No obstante, no se estableció garantía sobre Almadén, como querían los banqueros, que veían cercano el fin del contrato de Ezpeleta $^{19}$.

Sin embargo, cuando la noticia del acuerdo llegó a Madrid, el Conde de Toreno, ministro desde el 18 de junio de 1834, se negó a aceptarlo, dejándolo en suspenso, para firmar sobre la marcha otro convenio con el banquero Ardoin, con el que se había comprometido en una compleja operación de arreglo de la deuda, reforma impositiva y devaluación del real. En este plan los Rothschild estaban de más, ya que no se comprometían a ninguna operación fuera de su préstamo, y estaban de más las cláusulas de su contrato, con las cuales era imposible negociar con otro interlocutor. Ardoin, por el contrario, se mostraba dispuesto a emitir un empréstito y a saldar el préstamo ${ }^{20}$.

Los Rothschild, en todo caso, se dieron prisa por recuperar su dinero. Un empleado de la Casa fracasó en julio, así que Nathan Rothschild mandó a Madrid a su hijo Lionel ${ }^{21}$ para que negociara el reintegro del préstamo y evitara que Toreno pudiera incluir el mercurio de Almadén en cualquier combinación de empréstito.

Lionel hizo bien su trabajo y, tras diez meses de negociaciones, consiguió la devolución del préstamo y el contrato del mercurio de Almadén por otros tres años, tras un flagrante fraude en la subasta y un soborno bien documentado a la Reina y al propio Toreno ${ }^{22}$. El Ministro consiguió, por su parte, que los Rothschild apoyaran la conversión de 5.527 millones de reales emitidos por las Cortes y Aguado

${ }^{19}$ Este punto no había sido aceptado por Miraflores. Vid. Miraflores (1964, pp. 36, 39, 63-65 y 223-225).

${ }^{20}$ Véanse Martín (1980 pp. 167-169), Fontana (1977, pp. 44-58 y 64-70) y Sardá (1970, pp. 77-79).

${ }^{21}$ Dato proporcionado por Ferguson (1998, pp. 297-298 y 383, nota 46).

${ }^{22}$ En concreto, 4.962.100 reales a Toreno y una donación a la lista civil de la Reina de entre 2 y 6 millones de reales. Citado por Gille (1965, p. 251), Fontana (1977, p. 80) y Corti (1928, p. 127). 
en el extranjero en los nuevos tipos de deuda: consolidada al 5 por cien, pasiva y diferida, que se aplicó a los intereses atrasados de toda la deuda reconocida ${ }^{23}$. La operación sería muy importante, aunque la estancia de Lionel se saldaría con otros dos logros: el principal sería la creación de una agencia estable en Madrid, de la que se encargaría el joven Daniel Weisweiller, que se destaparía pronto como el más eficiente de los agentes de los Rothschild en el extranjero ${ }^{24}$; junto a ello, la familia asumió la corresponsalía del Banco de San Fernando en Londres y París ${ }^{25}$, que a posteriori se convertiría en la base de buena parte de sus operaciones en España.

\subsection{6-1840: El negocio de la Guerra Carlista}

Según la historiografía, el nombramiento de Mendizábal fue fruto de los consejos del embajador inglés Villiers a María Cristina, por considerar que era «la única persona de este país que goza de la total confianza de los mercados financieros extranjeros, cosa absolutamente indispensable para enfrentar la presente crisis financiera» ${ }^{26}$. El dinero foráneo no fue precisamente el que pagó la Guerra Carlista, pero Mendizábal sí resultó ser el único con las ideas claras para sacar al país de su crisis institucional y cerrar el conflicto. Su programa se concretaba en una leva general y en una combinación de medidas para expandir el crédito con otras dirigidas a liberar de cargas al Estado, con el fin de derivar fondos al frente. En un principio, la primera recaudación vendría de las exenciones de la misma leva -4.000 reales por persona-, que reportaron 46 millones de reales durante su ministerio, en tanto que la reducción de la carga financiera giraría alrededor de su célebre desamortización eclesiástica y un empréstito en Gran Bretaña, para el que Mendizábal contaba con los Rothschild, imaginando que podría repetir con ellos la experiencia de Portugal ${ }^{27}$. Los banqueros, sin embargo, discrepaban de la eficiencia de las resoluciones del Ministro y especialmente de las posibilidades a corto plazo de la desamortización ${ }^{28}$, por lo que fue imposible cerrar ningún acuer-

\footnotetext{
${ }^{23}$ Véase Artola (1986, pp. 168-169).

${ }^{24}$ Opinión de Ferguson (1998 p. 301).

${ }^{25}$ Cartas de 19/9/1835 y 22/3/1836, ABE Secretaría, legajos 1196 y 1259.

${ }^{26}$ Citado por Marichal (1980, p. 104).

${ }^{27}$ Mendizábal obtuvo también 19 millones de reales a través de una operación de intercambio camuflado de deuda activa por pasiva y diferida exterior. Fontana (1977, pp. 135-145) y Artola (1986, p. 171).

${ }^{28}$ Se oyó decir a Nathan Rothschild, mostrando su incredulidad sobre su viabilidad para el pago de la deuda de 1836, que la desamortización era: «...como decirme a las siete de la tarde, cuando quiero mi cena, que hay una vaca pastando en el campo a una milla de distancia». Citado por Ferguson (1998, p. 386).
} 
do. No obstante, parece que la familia tenía previsto discutir sobre un posible empréstito a España en una reunión en la que se produjo el súbito fallecimiento de Nathan Rothschild ${ }^{29}$.

Nathan acertó en sus sospechas, puesto que el Tesoro tardaría años en notar los efectos de la venta de bienes de la Iglesia ${ }^{30}$. Se equivocaría también el Ministro en su previsión de gastos, ya que el Ejército del Norte absorbió rápidamente las partidas enviadas. Por lo tanto, Mendizábal tuvo que apoyarse en un préstamo forzoso de 200 millones de reales sobre los mayores contribuyentes y en una serie de préstamos a corto plazo del Banco de San Fernando, que en los meses siguientes fue extendiendo a banqueros y comerciantes madrileños como Safont, Tapís, Alcober y Alabau, y a otros extranjeros, como Ricardo. A falta de otros recursos, estos adelantos se acordaron a cambio de billetes del Tesoro, unos valores oficiales que se entregaban con descuento $\mathrm{y}$, fundamentalmente, en letras sobre los impuestos de las provincias o las colonias de Ultramar, en especial Cuba, denominadas en este caso libranzas sobre Cajas de la Habana ${ }^{31}$. Estas últimas, sin embargo, al acordarse sin coordinación entre las tesorerías de la Isla y la Península, sufrían retrasos considerables en su pago. La asunción de este riesgo hubo que compensarlo con otro sustancioso descuento, que iba del 18 por cien, en las libranzas sobre la Habana, hasta un 33 por cien en las de Manila, así como la posibilidad de hacer parte de los avances con letras impagadas del Estado, por lo que la cantidad efectiva adelantada era pequeña si el contratista recogía valores devaluados del mercado presentándolos por todo su nominal. En estas condiciones, el descalabro para la Hacienda llegaba a alcanzar el 60 por cien. Aún así, el giro de libranzas fue muy importante desde 1836, y mucho más a partir de la subida de impuestos en Cuba decretada por Pita Pizarro en $1838^{32}$. Estas figuras, en definitiva, constituyeron la base de lo que comenzó a denominarse como deuda flotante del Estado, la cual debía funcionar independientemente del resto del pasivo del Tesoro. A la larga, esto se hizo imposible, ya que esta deuda estuvo vinculada desde su creación a determinados tributos e incluso a la deuda consolidada, toda vez que el Tesoro emitió títulos para garantizar los contratos. Tales garantías amenazaban con hundir la cotización aún más, caso de ser liquidadas.

\footnotetext{
${ }^{29}$ Véanse Otazu (1987, p. 51) y Ferguson (1998, p. 313). Después de eso, lo más que consiguió Mendizábal de los Rothschild fue un adelanto de 100.000 libras sobre los ingresos del mercurio. Contrato de 6/11/1836, Archivos Rothschild Frères, Centre des Archives du Monde du Travail, (en adelante ARP) 132AQ 40.

${ }^{30}$ En 1836 tan sólo se pudo recoger deuda por 18 millones de reales nominales, frente a los 80 de 1837 y los 108 de 1838. Vid. el resto de los datos, hasta 1842, en Artola (1986, p.181).

${ }^{31}$ Véanse Tedde (1999, p. 62), Artola (1986, pp. 185-187) y Janke (1974, p. 261).

32 Vid. Sáiz (1991), Fontana (1977, p. 234), Otazu (1987, pp. 48-50) y Santillán (1960, v. 1, p. 219).
} 
Los Rothschild no estuvieron en principio interesados en estos contratos; no así Weisweiller, que en 1836 comenzó a recibir propuestas de Manuel Gaviria, el intendente de la Casa Real, para tomar conjuntamente las libranzas del Tesoro y las que correspondían a la Corona ${ }^{33}$. El agente consiguió vencer la resistencia de sus patronos, y los contratos con Gaviria, en los que influyeron mucho sus contactos con la Regente, se intensificaron en los años siguientes. El cúmulo de operaciones llegaría a ser tan importante que en 1838 los Rothschild enviaron a su agente Karl Scharfenberg a La Habana con la misión de acelerar el pago de las operaciones pendientes y remitir los fondos a Londres y Nueva York ${ }^{34}$.

\section{CUADRO 1 \\ PARTICIPACIÓN DE LA CASA ROTHSCHILD Y ASOCIADOS EN EL CONJUNTO DE LOS ADELANTOS AL TESORO, 1836-1840 \\ (Reales de vellón)}

\begin{tabular}{|c|c|c|c|}
\hline Años & $\begin{array}{c}\text { Anticipaciones de la } \\
\text { Casa Rothschild y } \\
\text { asociados }\end{array}$ & $\begin{array}{c}\text { Anticipaciones totales } \\
\text { al Tesoro }\end{array}$ & $\begin{array}{c}\text { Porcentaje } \\
\text { de la Casa } \\
\text { Rothschild }\end{array}$ \\
\hline 1836 & 10.244 .000 & 67.300 .000 & 15,2 \\
\hline 1837 & 34.500 .000 & 148.900 .000 & 23,2 \\
\hline 1838 & 98.500 .000 & 126.600 .000 & 77,8 \\
\hline 1839 & 50.734 .140 & 206.700 .000 & 24,5 \\
\hline 1840 & 82.000 .000 & 479.143 .060 & 17,1 \\
\hline Totales & 275.978 .140 & 1.028 .643 .060 & 26,8 \\
\hline
\end{tabular}

Fuente: ARP132AQ 40 y 41, ABE Secretaría leg. 1138, Otazu (1987, pp. 50-55, 6062, 78-79, 95, 98-102, 111-113 y 121-123), Martín (1980, pp. 195-199 y 205) y Memoria de Pita Pizarro de 1840, salvo 1840, tomado del Diario de Sesiones del Congreso, apéndice $n^{\circ} 13,1 / 4 / 1841$.

En conjunto, si comparamos estas cifras con el conjunto las anticipaciones hechas al Tesoro durante la guerra, confirmamos que estos contratos supusieron

${ }^{33}$ María Cristina y su hija tenían asignados 40 millones de reales de los presupuestos del Estado, aparte del disfrute de los Reales Sitios, que tenían asignados otros 12 millones. Véase Otazu (1987, pp. 119-120).

${ }^{34}$ Vid. Otazu (1987, pp. 83-84) y Calavera (1991). De acuerdo con Tedde (1999, pp. 126127), Scharfenberg actuó con tanta eficacia que el Banco de San Fernando requirió sus servicios para desbloquear sus cuentas en 1840. 
una parte muy importante de la deuda flotante del Estado en el periodo ${ }^{35}$. Sobresalen de manera significativa las cifras de 1838, cuando los Rothschild tuvieron que adelantar 50 millones de reales para renovar el contrato de Almadén ${ }^{36}$. A estas cantidades habría que sumar otros 66,3 millones adelantados a la Corona y los algo más de 142 millones que percibió el Tesoro de los Rothschild por la venta de azogues durante el mismo periodo ${ }^{37}$. Indudablemente, estas operaciones supusieron una cifra mayor de la que hubiera resultado si los Rothschild hubieran negociado cualquiera de los empréstitos que les ofrecieron, aunque a unos réditos para ellos mucho mayores que la simple comisión por emitir en bolsa.

\subsection{El «arreglo» de la deuda de 1851}

Diez años después de finalizar la Guerra Carlista, el Estado todavía no había pagado su factura, ni menos aún había podido hacer frente a las deudas suspendidas por el conflicto. En 1841 Fernández Gamboa capitalizó 1.200 millones de reales en intereses de la deuda sin abonar desde 1836, que se intercambiaron por el nuevo 3 por cien consolidado. Alejandro Mon quiso completar la operación en 1844 con la conversión de la deuda flotante, que serviría para recuperar las contribuciones afectadas, sin lo cual sería imposible la reforma tributaria que preparaba. Por consiguiente, el Tesoro negoció con los acreedores el intercambio de sus derechos por títulos al 3 por cien. Eso benefició a la mayoría, que recibió en todo su valor una cantidad que había adelantado en valores devaluados ${ }^{38}$. Weisweiller no convirtió nada, puesto que no había firmado contratos en los meses previos, pero sí participó en las operaciones dando salida a la enorme cantidad de títulos que quedaron en manos de Salamanca y Agustín Muñoz, el marido de la antigua Regente. De esta manera, entre febrero y junio de 1845, vendió en su nombre, en París, 130 millones de reales del 3 por cien consolidado ${ }^{39}$.

${ }^{35}$ En total fueron 24 operaciones, de las cuales 11 las tomaron en solitario, 11 se firmaron con Gaviria, una con Gaviria y Collado, otra con Gaviria y Fagoaga y una última con Mariano Bertodano.

${ }^{36}$ El contrato, firmado el 20/9/1838, liberaba de la obligación de un empréstito, aunque exigió a la Casa Rothschild que igualase la oferta de Aguado, de 60 pesos (1.200 reales) el quintal. Vid. Martín (1980, p. 205).

${ }^{37}$ Documentado en Martín (1980). Están incorporados 82,5 millones de reales, descontados de la venta de azogues.

${ }^{38}$ El Estado asumía 58 millones de reales al año por intereses de 1.948 millones de la deuda entregada para saldar 710 millones en adelantos y recuperar garantías por 245 millones. Véase Martín (1980, p. 213).

${ }^{39}$ A ésta se unió otra colocación de 700.000 libras del 5 por cien exterior en Londres. Citado en Otazu (1987, pp. 207-218). 
Quedaba aún pendiente el capítulo de la deuda generada desde el Trienio hasta 1834, cuya resolución se había dado por perdida desde Mendizábal ${ }^{40}$. Los portadores de deuda española se quejaban de que el Gobierno les hubiera abandonado y que no hubiera tomado ninguna medida, salvo la capitalización de 1841. Desde entonces, los impagos se habían vuelto a acumular, ya que sólo se hacía frente al servicio del 3 por cien $^{41}$.

Los miembros del Committee of Spanish Bondholders de Londres y los de las demás bolsas europeas tomaron la palabra a Narváez a fines de 1847, cuando prometió solemnemente dar una rápida y justa resolución al problema ${ }^{42}$. Una comisión, creada al efecto, estudió las demandas de los distintos acreedores y propuso varias medidas, todas en la línea de reducir el montante de la deuda para poder hacer frente al pago de intereses, aunque existían dudas sobre si la posible conversión debía ser o no voluntaria y si los títulos debían valorarse según algún criterio previo o según su cotización ${ }^{43}$. El mismo Commitee, siempre a través de Weisweiller, quiso intervenir en el debate y propuso un plan alternativo, sin plantearse reducción ninguna, por el que los intereses no cobrados desde 1841 volvieran a capitalizarse en títulos de 3 por cien consolidado, abriéndose a la posibilidad de reducir temporalmente la cuantía de los intereses de la Deuda, siempre que las percepciones parciales se hicieran en metálico ${ }^{44}$.

Sin embargo, el 1 de febrero de 1851, apenas estrenada su jefatura de Gobierno, Bravo Murillo presentó un proyecto de ley que modificaba todas las propuestas. En el caso de la deuda exterior, el borrador sólo mantenía tal cual el 3 por cien consolidado, pero los viejos títulos de deuda al 5 por cien no recibirían más que una parte de sus intereses, que se incrementarían gradualmente en diecinueve años, hasta llegar al 3. Los intereses atrasados se reducían, por obra y gracia de la ley, a la mitad, para convertirse con los anteriores en una nueva deuda diferida. Por último, se creaba el amortizable de segunda clase, que englobaría los demás títulos pendientes de canje ${ }^{45}$. En definitiva, se trataba una quiebra encubierta, como muchos autores han recalcado ${ }^{46}$, en la que el Estado español reconocía que no podía pagar sus deudas, por muy solemnes que hubieran sido sus promesas.

\footnotetext{
${ }^{40}$ Recordemos que en 1835, por intermediación de los Rothschild, los acreedores habían aceptado la conversión de sus títulos y la pérdida de parte de los nominales, que aún circulaban como deuda pasiva.

${ }^{41}$ A fines de 1849 el Estado reconocía deudas por 14.974 millones de reales, de los que 1.469 correspondían a intereses atrasados del antiguo 5 por cien. Véase Sánchez Ocaña (1855, p. 402) y Documentos relativos al arreglo general de la deuda del Estado (1851, p. 109).

42 Carta de los Comités a Narváez de 18/12/1847, en Documentos (1851, pp. 50-51).

${ }^{43}$ Véanse Documentos (1851), Artola (1986, pp. 267-269) y Carrera Raya (1987, pp. 58-59).

${ }^{44}$ Memorándum de los Comités de 30-6-1849. Documentos (1851, pp. 52-61).

${ }^{45}$ Incluida en esta última la deuda pasiva. Proyecto de Ley de 1/2/1851, Documentos (1851, pp. 5-9).

${ }^{46}$ Entre otros, Tortella, Cameron, Comín, Artola, Tedde, Estapé o Carrera Raya.
} 
Alejándonos de cualquier argumento jurídico, político o económico sobre el tema, lo que llama la atención de este proceso es la falta de diálogo con los acreedores para llegar a un acuerdo. Es significativo que, cuando se presentó el proyecto, la aparente intransigencia de los tenedores británicos se quebró, puesto que Weisweiller remitió una nota a Bravo Murillo en la que aseguraba que éstos aceptaban todos los cambios, excepto la reducción de los intereses atrasados ${ }^{47}$. Aceptar esta modificación no hubiera supuesto un gran desembolso, pero el político se negó a cambiar su proyecto, que se convirtió en Ley el 1 de agosto de 1851. Automáticamente, el Comité de Londres solicitó de nuevo la no admisión de títulos españoles en su Bolsa. Ello no debía importar al Ministro, que no pensaba emitir nada en el extranjero, pero a la larga sí afectaría a sus sucesores, que vieron cerrado su crédito fuera de España por dos décadas.

\subsection{La autosuficiencia temporal del Tesoro. 1858-1863}

Las reformas de Bravo Murillo no sirvieron para acabar con los problemas de endeudamiento. Los expedientes de deuda flotante continuaron, aunque contenidos, al menos hasta la crisis de 1854-55, que disparó los contratos y obligó a Madoz a presentar su propuesta de desamortización general y a intentar emitir un empréstito -interior y exterior- de 375 millones de pesetas en títulos de 3 por cien ${ }^{48}$. Como no podía ser de otra manera, el Ministro no tardó en recibir un toque de atención por escrito de Daniel Weisweiller e Ignacio Bauer, que se había unido ese año a la agencia, en el que afirmaban que la Casa Rothschild y los portadores de deuda española antigua no estarían dispuestos a permitir una nueva emisión en tanto no se resolviera el abono de los intereses repudiados en $1851^{49}$. Madoz renunció al empréstito y tuvo que recurrir a nuevos adelantos, en los cuales los Rothschild, por cierto, también tomaron su parte ${ }^{50}$.

La situación no se alargó en el tiempo, pues el país comenzó a beneficiarse del desarrollo de las inversiones ferroviarias y bancarias posterior a 1856. Estos avances se dejarían notar en el campo de la Hacienda, que incrementó sus ingresos por encima del 50 por cien, rompiendo su natural tendencia al estancamiento, a lo que se unieron las facilidades dadas por la desamortización y el inesperado protagonismo de la Caja General de Depósitos (CGD). La CGD, que

\footnotetext{
${ }^{47}$ Carta de Weisweiller a Bravo Murillo de 19/2/1851, en Documentos (1851, p. 97).

${ }^{48}$ Carta de Weisweiller y Bauer 14/2/1855, ARP 132AQ6152.

${ }^{49}$ Carta de 7/3/1855 de Weisweiller y Bauer, en nombre del Committee, a Madoz, ARP 132AQ 6152.

${ }^{50}$ En concreto, tomaron dos libranzas en 1855, una de 225.000 y otra de 167.590 pesos, sobre Manila y La Habana. Cuentas ML 1855 y FC 1855, ARL, I/I/30.
} 


\section{GRÁFICO 2 \\ EVOLUCIÓN DEL DÉFICIT PRESUPUESTARIO, LA DEUDA FLOTANTE DEL TESORO Y LOS DEPÓSITOS DE LA CGD \\ (1850-1882)}

(Millones ptas. a fin de año)

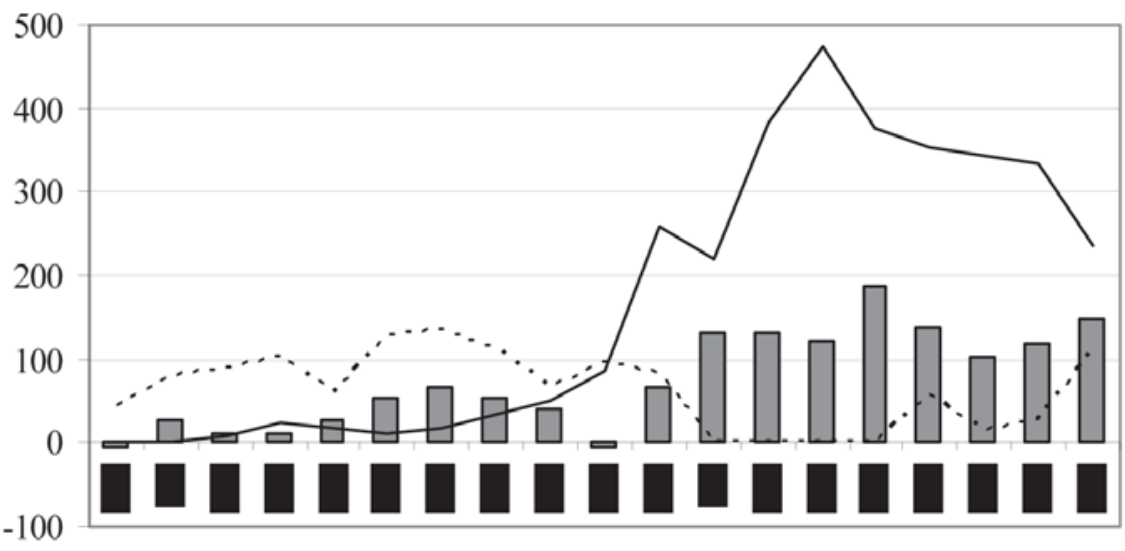

Déficit presupuestario

Total deuda Flotante del Tesoro

- Depositos en Metálico y cuentas corrientes de la CGD

Fuentes: Comín (1989, pp. 443-444), Fernández Acha (1976, pp 319-325) y Gonzalo González (1981, pp. 455-471).

había sido uno de tantos proyectos de Bravo Murillo, había vegetado durante un lustro con paupérrimos balances ${ }^{51}$. Sin embargo, a partir de 1858 la institución experimentó un espectacular incremento en las imposiciones, que crecieron hasta los 472,4 millones de pesetas en 1863. Para el Gobierno esta situación suponía un inestimable legado, puesto que los recursos de la CGD no tenían otra función que surtir de fondos al Tesoro, ayudando a cubrir su déficit (véase Grafico 2). La CGD, además, abonaba un interés del 5 por cien a los capitales depositados, mucho menor que el coste de la deuda flotante. Las cuentas del

${ }^{51}$ Esta institución, hecha a imagen de otra francesa, debía recoger fondos dispersos de la Administración -fianzas, consignaciones, depósitos, etc.- y habilitar cuentas corrientes a particulares. Sobre ella, véase Gonzalo (1981). 
Tesoro mejorarían tanto que el Gobierno de la Unión Liberal pudo iniciar una efímera política colonialista en Santo Domingo y Marruecos y subvencionar parte de la construcción ferroviaria ${ }^{52}$.

En este contexto se confirmó un cierto enfriamiento en las relaciones entre los Rothschild y el Tesoro, que se reforzó aún más con la pérdida del negocio de Almadén, merced a la voluntad del Gobierno de recuperar la gestión de las ventas de sus azogues ${ }^{53}$. No obstante, los Rothschild compensaron estas pérdidas con la apertura de nuevos negocios, como la comercialización de tabaco y plomo que, sin embargo, quedaron en un segundo plano cuando los banqueros decidieron reeditar en España su competencia con los Pereire por la construcción de las principales vías ferroviarias ${ }^{54}$. También se reforzaron sus relaciones con el Banco de España, con el que cerraron importantes operaciones de venta de oro. La primera data de 1852, cuando acordaron una entrega de 120.000 libras en oro, a la que siguió otra de 10 millones de francos en 1853, en pleno proceso de salvamento del San Fernando tras la incorporación del Banco de Isabel $\mathrm{II}^{55}$. Pero las ventas quedaron ahí; en parte por el interés del Banco por restringir su pasivo y en parte por la reforma monetaria de 1854, que reanudó las acuñaciones de oro a una paridad más acorde con los precios internacionales ${ }^{56}$. Las ventas se recuperarían en 1860, cuando el Ministro Salaverría decidió modificar las condiciones de las cuentas de la CGD y el Banco de España tuvo que hacerse cargo temporalmente de sus operaciones ${ }^{57}$. Durante unos meses el Banco vio menguar sus reservas y sufrió un conato de pánico financiero, que la Dirección salvaría retirando parte de sus billetes, restringiendo descuentos y préstamos y comprando a los Rothschild ingentes cantidades de pasta metálica, que totalizarían 161 millones de pesetas hasta $1863^{58}$.

52 De acuerdo con los datos de Comín (1988, vol. 1, pp. 350 y 366), los gastos en Fomento subieron del 8,6 por cien en 1856-59 al 11,2 por cien en 1860-1864, el mayor porcentaje en servicios económicos del presupuesto hasta después de 1920.

${ }^{53}$ El episodio ha sido descrito por Martín (1980, pp. 254-259).

${ }^{54}$ Véanse López-Morell (1999b y 2003) y Otazu (1987, cap. 4).

${ }^{55}$ ABE, Secretaría, caja 1015.

${ }^{56}$ Las operaciones de corresponsalía seguirían, y el Banco encargó a los Rothschild el pago de la deuda exterior en 1858. Carta de Weisweiller y Bauer a Santillán de 11/6/1858, ABE, Secretaría, Caja 1015.

${ }^{57}$ Real Decreto de 12/5/1861, recogido por Gonzalo (1981, pp. 516-522).

${ }^{58}$ El tipo de interés se elevó del 5 al 7 por cien, y el volumen de billetes del Banco pasó entre junio y septiembre de 1861 de 273,3 a 162,1 millones de reales. Vid. Sardá (1970, p. 145). Sobre las compras de oro, véase el Apéndice 1. El Banco solicitó a los Rothschild dos adelantos por valor de 7.500.000 francos para acelerar las compras: ABE, Secretaría, Legajo 733, y carta de Weisweiller y Bauer de 17/8/1861, ARP 132AQ 6171. 


\subsection{4-1874: una crisis mal resuelta}

El ciclo de crecimiento tocó techo en 1864, con una crisis que colapsó la actividad industrial y comercial del país, arrastrando en su caída a las finanzas públicas y degenerando en una grave crisis política.

El primer signo de debilidad en la Hacienda fue la paralización de las cuentas de la CGD a fines de 1863 (véase Gráfico 2), que Salaverría intentó compensar con un plan de emergencia basado en tres medidas de choque: liquidación de la deuda de la CGD, a partir de una emisión de 325 millones de pesetas en billetes hipotecarios al 6 por cien y otra de 150 millones en títulos de 3 por $\operatorname{cien}^{59}$; una reforma monetaria que dio lugar al escudo, y, por último, el primer impuesto sobre el ferrocarril, además del cese de las subvenciones a la construcción de líneas ${ }^{60}$. Sin embargo, el plan fracasó, empezando por la primera de las medidas, que se antojaba la más urgente, y, lo que es peor, provocó la retirada paulatina de los fondos de la CGD, que terminó dándole la puntilla ${ }^{61}$.

Para evitar el colapso se imponía la emisión de un empréstito que, obligatoriamente, tendría que lanzarse en el exterior y que exigiría el reconocimiento de las deudas repudiadas en 1851. Salaverría y Mon intentaron que los Rothschild avalaran la operación, que los banqueros quisieron vincular a algún tipo de ayuda para su compañía ferroviaria (MZA ${ }^{62}$. Pero el acuerdo no sería posible por la caída del Gobierno de la Unión Liberal. Apenas un año más tarde, Alonso Martínez intentaría otra fórmula, basada en un ajuste de las cuentas del Estado y en la creación del Banco Nacional Español, de acuerdo con varias bancos británicos, que se saldó con otro fiasco ${ }^{63}$, para alivio del Banco de España y de los Rothschild, que se hubieran visto desplazados de las operaciones.

El contrapunto a estos mandatos lo puso el Ministro conservador Barzanallana, que se negó a aceptar las medidas de sus dos colegas por considerar cualquier vuelta atrás en el arreglo como un atentado al orgullo nacional, y a pesar de las presiones del Gobierno francés, que prohibió cualquier emisión en París si no se aprobaban medidas de apoyo a las compañías ferroviarias ${ }^{64}$. Mientras tanto, consi-

\footnotetext{
${ }^{59}$ Los billetes tienen su origen en una ley de 1853, y se habían utilizado profusamente para pagar las campañas en el extranjero en 1860. Al respecto véanse Santillán (reed. 1960, vol. 2, p. 191), Artola (1986, p. 308), Gonzalo (1981, apéndice y pp. 488 y ss.) y Fernández Acha (1976, p. 313).

${ }^{60}$ Gaceta de Madrid de 28/5/1864 y Carta de Bauer de 15/8/1864, ARP 132AQ 6180.

${ }^{61}$ Como relatan Sánchez Albornoz (1968, pp. 9-10) y Gonzalo (1981, p. 321), tan sólo se colocaron billetes por valor de 20,5 millones de pesetas.

${ }^{62}$ Cartas de Weisweiller y Bauer de 7 y 19-31 de agosto y del 1 al 9/9/1864, ARP 132 AQ6180.

${ }^{63}$ Gacetas de Madrid de 5/4/1866, 8/5/1866 y 25/4/1866 y Tortella (1973, pp. 277-278).

${ }^{64}$ Archivo del Ministerio Francés de Economía y Finanzas, B-31.189.
} 
guió cuadrar su presupuesto con un empréstito forzoso y buscó financiación a través de varias entidades extranjeras y en la propia Casa Rothschild, que adelantó los fondos para el pago del cupón de la deuda exterior de 1866, 1867 y $1868^{65}$. Uno de los préstamos, firmado el 22 de septiembre de 1866, dio lugar a la recuperación de los contratos de Almadén. Por esa razón, la mayor parte de los sucesivos adelantos se acordó como avance de las ventas de azogue, que se descontaron de la cuenta del Tesoro en la Casa de Londres.

Los Rothschild hubieran preferido un arreglo rápido de la deuda y la negociación de un gran empréstito, mejor que todos estos adelantos ${ }^{66}$. Sobre todo si éste hubiera servido para derivar fondos al ferrocarril. No obstante, la opción de continuar esta política representaba innumerables ventajas, ya que mantenía para sus fondos un flujo continuo de alta rentabilidad, que aprovechaba las sinergias con otros negocios de la Casa sin apenas riesgo. Por ello, los Rothschild no quisieron forzar la situación.

En julio de 1867 Barzanallana claudicó, al menos aparentemente, y decidió dar salida al arreglo. Aceptaba la conversión en 3 por cien consolidado de la deuda amortizable, si se abonaba la diferencia entre su cotización y otra marcada, así como de los intereses impagados, aunque reduciendo su valor en un 75 por cien. Se anunció, además, la emisión de un empréstito exterior, diferente al de la conversión, con el fin de producir 100 millones de pesetas. De esta cantidad y de los beneficios de la conversión se retendría el 15 por cien para los ferrocarriles. En conjunto, 29 ó 30 millones, de los que Weisweiller y Bauer contaban con un 45 por cien para MZA. Por consiguiente, aconsejaron a sus patronos que presionaran al Gobierno francés y a los tenedores de deuda para cerrar el arreglo lo antes posible ${ }^{67}$.

La facilidad con que los acreedores británicos y franceses aceptaron los términos de la Ley ${ }^{68}$, tan lejos de sus reclamaciones primarias, sería otra muestra de la influencia que ejercían los Rothschild sobre los Committees, cuyo visto bueno permitió que la operación de canje fuera un éxito ${ }^{69}$. La contrapartida serían los 15 millones de pesetas anuales por intereses de los nuevos títulos, aunque al menos el Ministro pudo burlar a los grupos extranjeros ralentizando sine die el emprés-

\footnotetext{
${ }^{65}$ ARP 132AQ41, ARL I/I/51-52 y XI/109/91-92 y Artola (1986, p. 309).

${ }^{66}$ De hecho, presentaron en 1865 un proyecto de arreglo con Baring. Carta del Committee of Spanish Certificates Holders a N. M. Rothschild \& Sons y Baring Brothers Co, de 13/3/ 1865, ARL XI/109/86.

${ }^{67}$ Cartas de Weisweiller y Bauer 14/5/1867, 28/6/1867 y 6/7/1867, ARL XI/109/91y 92.

${ }^{68}$ Carta de Weisweiller y Bauer de 26/7/1867, ARL XI/109/92.

${ }^{69}$ Según Artola (1986, p. 316) y Comín (1996, p. 162), se cambiaron 500 millones de pesetas en deuda al 3 por cien por 345 millones en títulos antiguos, y se recogieron 92,5 millones de la transformación de los amortizables.
} 
tito y la ley que debía ordenar las ayudas al ferrocarril, la cual ni siquiera se presentó a las Cortes ${ }^{70}$.

Cuando, en el otoño de 1868, se produjo la llegada al poder de los progresistas, la situación del presupuesto no era peor que la de 1864, pero Figuerola se empeñó en un plan de saneamiento, a seis años vista, tras el cual pretendía reducir progresivamente su endeudamiento y la presión fiscal ${ }^{71}$. Su proyecto pecaba de cierta precipitación y exceso de optimismo, en un momento en el que la cotización de los títulos españoles más solventes, que debían financiar las operaciones, rondaba el 9 por cien efectivo y subiendo. Sin embargo, no dudó en dar salida al empréstito aprobado el año anterior, que entregó íntegro a los Rothschild, y preparó una emisión de Bonos del Tesoro para saldar el pasivo de la CGD. Esta última conversión falló, como en 1864, dejando en precario los planes del Ministro, que tuvo que ganar tiempo emitiendo otro empréstito de 1.021 millones de pesetas a través del Banco de París. En abril de 1870 volvió a intentarlo con los bonos, apoyado por un préstamo de los Rothschild, que tenía como contraprestación la cesión de las ventas de Almadén por treinta años. Pero la liquidación se saldó con un nuevo fiasco.

Moret intentó salvar la situación saldando el contrato de los bonos con un nuevo empréstito que colocarían los Rothschild, quienes remitirían desde Londres y en oro todo lo recaudado, como en las anteriores operaciones. Fue éste el menos caro de los empréstitos emitidos durante el Sexenio -10 por cien de interés efectivo-, aunque también fue el que terminó con el equilibrio insostenible de la Hacienda, cuyo deuda se llevaba ya el 59,7 por cien de sus ingresos ${ }^{72}$. A partir de entonces el Tesoro sobrevivió a base de adelantos a corto plazo del Banco de España y de un grupo de banqueros conocido como el «Sindicato de Madrid», liderado por la Casa Urquijo-Arenzana, que llevaron a la deuda flotante a sus máximos niveles históricos (vid. Gráfico 3) y que no impidieron la suspensión del pago de los intereses de la Deuda. Los Rothschild quisieron evitar estas operaciones, algunas de dudosa legalidad, cuyo rendimiento no bajaba del 12-14 por cien y llegaba a duplicar esa cifra, pero al menos en dos ocasiones tomaron parte siguiendo los consejos que les llegaron desde su agencia en Madrid ${ }^{73}$. En parale-

\footnotetext{
${ }^{70}$ Barzanallana renovó sus préstamos y emitió 125.000 .000 ptas. en billetes hipotecarios, con lo que pudo cerrar su presupuesto. Los Rothschild no se negaron a prestarle otros 18 millones de francos: Carta de Weisweiller y Bauer 5/10/1867 y de Guillermo Ettling de 20-101867 y 9-11-1867. ARL XI/109/92-93.

71 Véase Martín Niño (1972, caps. 1 y 2).

72 Véase al respecto Comín (1989, p. 423).

${ }^{73}$ En una de ellas, en la que estaba en juego un préstamo sindicado de 700.000 libras, Bauer argumentaba lo siguiente: «si realmente os interesa continuar en el futuro con unas relaciones permanentes con el Gobierno Español para [los temas de] Almadén y el ferrocarril, creemos que [...] deberíais comprometeros en el asunto». La Rothschild aportaron 400.000 libras. Carta de 23/6/1872, ARL XI/109/109.
} 
lo, el Tesoro recibió otros créditos y avaló más emisiones de deuda a cambio de ciertos privilegios administrativos o de la cesión de patrimonio del Estado: en 1872 el Paribas -heredero del Banco de París- negoció un adelanto y un empréstito, que incluían el privilegio de fundar el Banco Hipotecario; en 1874 fue el Banco de España el que adelantó 125 millones de pesetas, esta vez a cambio del monopolio de emisión de billetes; e, intercalado entre ambos acuerdos, se sitúa un nuevo empréstito forzoso y la venta de las minas de Ríotinto (véase Cuadro 2). En este caso, la operación habría sido un éxito, de no haber sido porque el Gobierno de la República renegoció a la baja los pagarés que se le dieron en pago para retirar cupones de deuda impagados, con un quebranto de 31.386 .800 pesetas $^{74}$. Fue el último desatino de los demócratas del Sexenio, que llenaron de buenas intenciones la política nacional, pero que no supieron dirigir con acierto sus fuentes de financiación.

\subsection{6 y 1881: se cierra el círculo de los arreglos}

A fines de abril de 1876 Salaverría presentó sus presupuestos, en los que incluía un nuevo proyecto de arreglo de la deuda flotante. Hacía también oficial la suspensión del pago de los intereses de la Deuda, efectiva desde 1873, cuyos cupones pendientes ofrecía cambiar por un nuevo amortizable al 2 por cien nominal, de acuerdo con su intención de pagar sólo una parte de los intereses, que recuperarían gradualmente su nivel en los años siguientes. La conversión de la deuda flotante proponía vertebrarla a través de dos emisiones: una de 580 millones de pesetas, a través del Banco de España, basada en las nuevas Obligaciones del Banco y del Tesoro, y otra de 250 millones sobre la Renta de Aduanas, de la que se encargaría el Banco Hipotecario. Estos títulos se podrían adquirir en metálico o a cambio de los antiguos resguardos de la CGD, bonos del Tesoro, deuda de personal, acciones de carreteras y obras públicas, contratos pendientes de deuda flotante o los nuevos amortizables. Todo, a falta del visto bueno del Committee y de los prestamistas del Tesoro, portadores de deuda flotante ${ }^{75}$.

Los comités de deuda consolidada aceptaron a regañadientes los amortizables, aunque exigieron que el primer cupón reducido se abonara ese semestre ${ }^{76}$. El acuerdo sobre la deuda flotante, por su parte, se pudo concluir gracias a una reunión presidida por Cánovas, a la que acudieron el Banco de España, el Hipotecario,

\footnotetext{
${ }^{74}$ Vid. Flores (1981, p. 82).

${ }^{75}$ Cartas de Bauer de 18 y 24/4/4876, ARL XI/109/122 y Artola (1986) pp. 349-350.

${ }^{76}$ Ciertamente, los 60 ó 70 millones de pesetas de esta partida representaban un sacrificio asumible y mínimo frente a los impagos que se pretendían legalizar. Cartas de Bauer de 18 y 25/4/4876, ARL XI/109/122.
} 
CUADRO 2

PRINCIPALES OPERACIONES PARA LA OBTENCIÓN DE FONDOS FIRMADOS POR EL TESORO DURANTE EL SEXENIO

\begin{tabular}{|c|c|c|c|c|}
\hline $\begin{array}{l}\text { Fecha y } \\
\text { contratista }\end{array}$ & $\begin{array}{l}\text { Operación } \\
\text { (Objetivo) }\end{array}$ & Condiciones & $\begin{array}{l}\text { Liquido } \\
\text { recibido por el } \\
\text { Tesoro }\end{array}$ & $\begin{array}{l}\text { Obligaciones } \\
\text { generadas }\end{array}$ \\
\hline $\begin{array}{l}23 / 11 / 1868 \\
\text { Casa } \\
\text { Rothschild }\end{array}$ & $\begin{array}{l}\text { Emisión de } 322.580 .000 \\
\text { ptas. en títulos del } 3 \% \\
\text { exterior (Liquidar la CGD y } \\
\text { ayudas al Ferrocarril: } 15 \% \text { ) }\end{array}$ & $\begin{array}{l}\text { Emitido al } 33 \% \\
\text { Comisión: } 4{ }^{\prime} 25 \% .\end{array}$ & $\begin{array}{l}93.548 .200 \text { ptas. } \\
\text { (a descontar un } \\
15 \% \text { para las } \\
\text { Cías. } \\
\text { Ferroviarias) }\end{array}$ & $\begin{array}{l}9.677 .400 \text { ptas. } \\
\text { anuales. }\end{array}$ \\
\hline $\begin{array}{l}27 / 10 / 1868 \\
\text { Suscripción } \\
\text { pública }\end{array}$ & $\begin{array}{l}\text { Emisión de } 625.000 .000 \\
\text { ptas. en Bonos del Tesoro al } \\
6 \% \text { (Liquidar la CGD y } \\
\text { ayudas al Ferrocarril: } 15 \% \text { ) }\end{array}$ & $\begin{array}{l}\text { Emitido al } 80 \% \\
\text { (Amortizan a los } \\
20 \text { años) }\end{array}$ & $\begin{array}{l}110.064 .000 \\
\text { ptas. } \\
\text { (Solo se colocan } \\
\text { 138'8 millones } \\
\text { nominales) }\end{array}$ & $\begin{array}{l}8.328 .000 \text { ptas. } \\
\text { anuales }\end{array}$ \\
\hline $\begin{array}{l}15 / 4 / 1869 \\
\text { Banco de } \\
\text { París }\end{array}$ & $\begin{array}{l}\text { Emisión de } 1.021 .875 .750 \\
\text { ptas. en títulos de } 3 \% \\
\text { interior y exterior. }\end{array}$ & $\begin{array}{l}\text { Emitido al } \\
24 ' 46 \% \text { (Incluye } \\
\text { comisión) }\end{array}$ & $\begin{array}{l}250.000 .000 \\
\text { ptas. }\end{array}$ & $\begin{array}{l}32.498 .722 \text { ptas. } \\
\text { anuales }\end{array}$ \\
\hline $\begin{array}{l}22 / 3 / 1870 \\
\text { Banco de } \\
\text { París }\end{array}$ & $\begin{array}{l}\text { Emisión de } 350.000 .000 \\
\text { ptas. en Bonos del Tesoro al } \\
6 \% \text { (Liquidar la CGD y } \\
\text { cubrir el déficit del Tesoro) }\end{array}$ & $\begin{array}{l}\text { Emitido al } 66 \% \\
\text { (Amortizan a los } \\
20 \text { años) }\end{array}$ & $\begin{array}{l}42.340 .000 \text { ptas. } \\
\text { (Solo se colocan } \\
168 \text { millones } \\
\text { nominales) }\end{array}$ & $\begin{array}{l}10.705 .000 \text { ptas. } \\
\text { anuales }\end{array}$ \\
\hline $\begin{array}{l}28 / 4 / 1870 \\
\text { Casa } \\
\text { Rothschild }\end{array}$ & $\begin{array}{l}\text { Préstamo al Tesoro de } \\
40.266 .186 \text { ptas. } \\
\text { (Amortizar bonos del } \\
\text { Tesoro) }\end{array}$ & $\begin{array}{l}\text { Inter: } 8 \% \text { Comi: } \\
4 \% \text { Cesión de las } \\
\text { ventas de } \\
\text { Almadén }\end{array}$ & 40.266 .186 ptas. & $\begin{array}{l}3.651 .000 \text { ptas. } \\
\text { (30 anualidades) }\end{array}$ \\
\hline $\begin{array}{l}27 / 7 / 1871 \\
\text { Casa } \\
\text { Rothschild }\end{array}$ & $\begin{array}{l}\text { Emisión de } 487.717 .000 \\
\text { ptas. en títulos del } 3 \% \\
\text { exterior (rescindir contrato } \\
22-3-1870 \text { ) }\end{array}$ & $\begin{array}{l}\text { Emitido al } 299^{\prime} 5 \% \\
\text { Con deducción } \\
\text { del último cupón. }\end{array}$ & $\begin{array}{l}143.876 .515 \\
\text { ptas. }\end{array}$ & $\begin{array}{l}14.631 .510 \text { ptas. } \\
\text { anuales }\end{array}$ \\
\hline $\begin{array}{l}2 / 9 / 1872 \\
\text { Paribas }\end{array}$ & $\begin{array}{l}\text { Emisión de } 842.218 .000 \\
\text { ptas. en títulos del } 3 \% \\
\text { exterior e interior (Pago del } \\
\text { cupón y retirar letras } \\
\text { impagadas) }\end{array}$ & $\begin{array}{l}\text { Emitido al } 27 \% \text {. } \\
\text { Concesión del B. } \\
\text { Hipotecario. }\end{array}$ & $\begin{array}{l}236.331 .750 \\
\text { ptas. (Más un } \\
\text { adelanto de } 100 \\
\text { mill. Francos) }\end{array}$ & $\begin{array}{l}25.266 .540 \text { ptas. } \\
\text { anuales }\end{array}$ \\
\hline $\begin{array}{l}14 / 2 / 1873 \\
\text { Grupo } \\
\text { Matheson }\end{array}$ & $\begin{array}{l}\text { Venta de las minas de } \\
\text { Ríotinto (Reducir el déficit) }\end{array}$ & $\begin{array}{l}\text { Cesión por ley de } \\
\text { las minas de } \\
\text { Ríotinto. }\end{array}$ & $\begin{array}{l}92.756 .592 \text { ptas. } \\
\text { en } 10 \text { pagarés. }\end{array}$ & - \\
\hline $\begin{array}{l}25 / 8 / 1873 \\
\text { Banco } \\
\text { Hipotecario }\end{array}$ & $\begin{array}{l}\text { Emisión de } 300.000 .000 \\
\text { ptas. en billetes hipotecarios } \\
\text { al } 6 \% \text { (Reducir el déficit) }\end{array}$ & $\begin{array}{l}\text { Se desconocen las } \\
\text { condiciones. }\end{array}$ & $\begin{array}{l}\text { Solo emitieron } \\
110 \text { millones } \\
\text { antes de } 1875 . \\
\end{array}$ & $\begin{array}{l}6.600 .000 \text { ptas. } \\
\text { anuales }\end{array}$ \\
\hline $\begin{array}{l}25 / 8 / 1873 \\
\text { Suscripción } \\
\text { pública }\end{array}$ & $\begin{array}{l}\text { Empréstito Nacional en } \\
\text { títulos al } 6 \% \text { (Reducir el } \\
\text { déficit) }\end{array}$ & $\begin{array}{l}\text { Obligatorio entre } \\
\text { grandes } \\
\text { contribuyentes. }\end{array}$ & $\begin{array}{l}175.000 .000 \\
\text { ptas. }\end{array}$ & $\begin{array}{l}10.500 .000 \text { ptas. } \\
\text { anuales }\end{array}$ \\
\hline $\begin{array}{l}19 / 3 / 1874 \\
\text { Banco de } \\
\text { España }\end{array}$ & $\begin{array}{l}\text { Préstamo del Banco de } \\
\text { España a fondo perdido } \\
\text { (Reducir el déficit) }\end{array}$ & $\begin{array}{l}\text { Monopolio de } \\
\text { emisión de } \\
\text { billetes }\end{array}$ & $\begin{array}{l}125.000 .000 \\
\text { ptas. }\end{array}$ & - \\
\hline
\end{tabular}

Fuentes: ARP 132AQ41, ARL I/I/57-58, Martín Niño (1972 pp. 70-95) y Fernández Acha (1974). 


\section{GRÁFICO 3}

ESTADO DE LA DEUDA DEL TESORO EN CIRCULACIÓN, 1860-1885

(Millones ptas.)

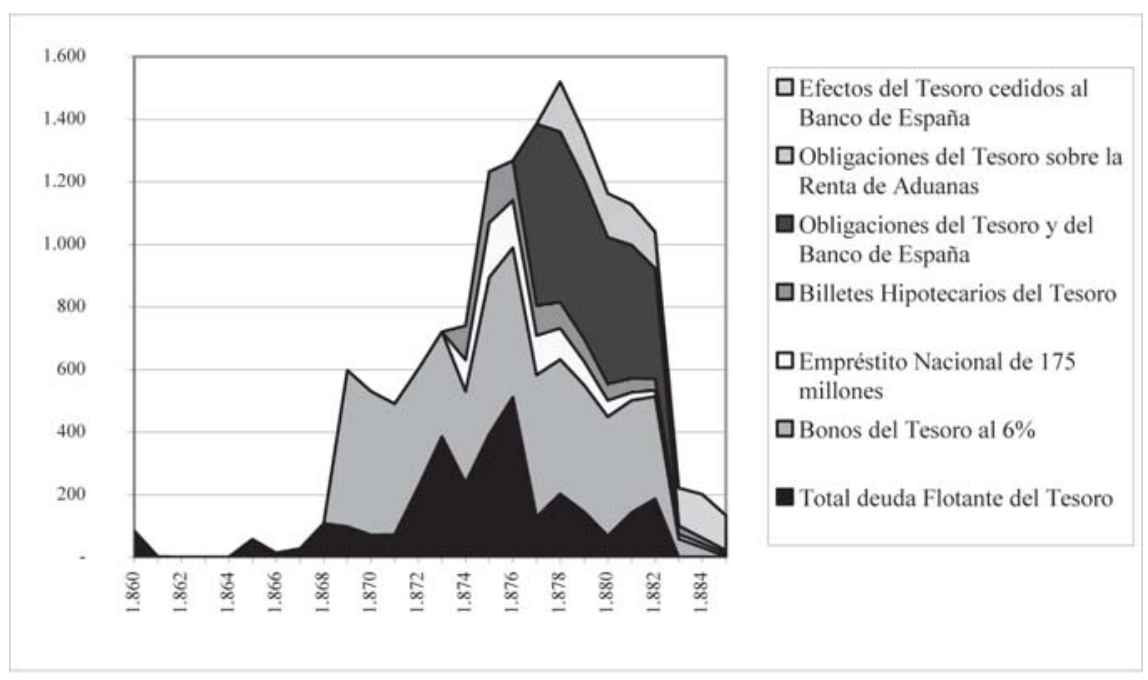

Fuente: Fernández Acha (1976).

Urquijo -representando al Sindicato de Madrid- y el propio Bauer. Cada uno obtuvo su beneficio e impuso sus condiciones en el encuentro: el Banco de España mostró su voluntad de emitir, aunque anunció que lanzaría sólo 330 millones de pesetas, reservando el resto en cartera; el Hipotecario se sumaría si se le confirmaban los derechos sobre la obligaciones de Aduanas; Urquijo, con la vista puesta en futuros adelantos, se comprometió a participar y a renovar sus letras pendientes al Tesoro, aunque éstas, todo sea dicho, rondaban entre el 15,20 y el 22 por cien de interés efectivo; Bauer, por último, expuso que la Casa Rothschild daría su apoyo, siempre y cuando el Gobierno abandonara varios proyectos sobre legislación ferroviaria y accediera a pagar el cupón como pedían los Comités ${ }^{77}$.

Con el fin de sacar adelante la emisión de sus obligaciones, el Banco de España presionó a los Rothschild para que le adelantaran 60 millones de francos, a lo

\footnotetext{
${ }^{77}$ Bauer convenció a los Rothschild de la necesidad de participar en la operación con el clásico argumento: «creemos que es esencial para todos nuestros negocios en España y por continuarlos el mayor tiempo posible». Cartas de 23 y 30/6/1876, ARL XI/109/122-123.
} 
que éstos se negaron en redondo ${ }^{78}$, aunque sí tomaron 30 millones de la emisión, con la promesa de tomar otros 10 en caso de apuro. Por lo demás, el Banco logró reunir a un concurrido grupo de capitalistas madrileños y extranjeros, que garantizó la colocación de entre un 48 y un 66 por cien de los títulos del primer paquete de la emisión, al que siguió el resto en $1878^{79}$.

La operación de saneamiento la cerraría Camacho en 1881, cuando la deuda del Estado alcanzaba los 12.590 millones de pesetas y 1.162 la del Tesoro, exigiendo el abono de 315 millones anuales en intereses y amortizaciones, sin contar los dos puntos pendientes de pago de la deuda consolidada, que sumarían otros 200 millones. Camacho propuso ahondar en la línea del arreglo de Salaverría, aprovechando un momento favorable en lo mercados financieros y un proyecto de conversión previo de Gos-Cayón ${ }^{80}$. De esta manera, anunció la emisión de 1.800 millones de pesetas en una nueva deuda, al 4 por cien de interés, que se amortizaría en 40 años y que podría adquirirse a cambio de obligaciones del Banco o de Aduanas, por amortizables al 2 por cien, reconocidos al 50 por cien, y por deuda flotante $\mathrm{u}$ otras partidas pendientes ${ }^{81}$.

Hubo un asentimiento general a las condiciones propuestas, salvo la del precio del 85 por cien para los nuevos títulos, que fue recibido con incredulidad por los políticos y banqueros de Madrid ${ }^{82}$. Pero el Ministro no quiso cambiar nada, excepto una subida en la opción del amortizable exterior, que pasó al 54 por cien, respaldado por un acuerdo con el Banco de España y los Comités extranjeros, con los que Camacho estuvo reuniéndose y carteándose desde agosto ${ }^{83}$. El proyecto se convertiría en Ley el 9 de diciembre de 1881.

Frente a lo que habían sostenido sus detractores, el público acogió con entusiasmo la emisión, y en unos meses se intercambiaron todas las obligaciones del Banco y de Aduanas, así como la mayor parte de los amortizables y los bonos del Tesoro $^{84}$. El resultado de la conversión animó a Camacho ampliarla al conjunto de las deudas consolidadas. Esta vez su oferta a los portadores de deuda al 3 por cien y de obligaciones ferroviarias consistió en la transformación de los intereses nominales de sus títulos al 4 por cien, modificando proporcionalmente el capital.

${ }^{78}$ Cartas de Bauer de 27 y 30/6/1876, ARL XI/109/122-123.

${ }^{79}$ El Banco volvió a ofrecer a los Rothschild 50.000 obligaciones de la serie exterior, a 465 francos, el 93 por cien. Cartas de Bauer de 20 de febrero, 15 de marzo, 31 de mayo y 1/6/1878, ARL, XI/110/9.

${ }^{80}$ Vid. Comín (1996, p. 164).

${ }^{81}$ Las Acciones de Obras Públicas se reconocerían al 76 por cien, y al 80 la Deuda de Personal. Resumen del proyecto de 30-9-1881, ARL XI/92/0A, citado también por Fernández Acha (1976, p. 711) y por Comín (1996, pp. 164-165).

82 Incluido el propio Bauer. Cartas de Bauer de 12, 13, 17 y 18/10/1881, ARL XI/92/0A.

${ }^{83}$ Nos constan contactos directos con el Comité, directamente o través de los Rothschild, desde el 31/8/1881. Cartas de Bauer de las mismas fechas y de 14/10 y 4/11/1881, ARL XI/92/0A.

${ }^{84}$ Los intereses en juego se redujeron de 169,5 a 86,9 millones de pesetas anuales. 
La Ley de 29 de mayo de 1882 confirmaría la propuesta, que el Committee no quiso aceptar para la deuda exterior al 3 por cien hasta que se le prometió una comisión del 0,87 por cien para los títulos que se intercambiaran en los primeros dos meses, un abono al Comité de 50.000 libras, de difícil catalogación, y el derecho a cobrar los intereses en oro y a un cambio fijo a libras y francos ${ }^{85}$.

\section{GRÁFICO 4}

EVOLUCIÓN DE LA DEUDA DEL ESTADO EN CIRCULACIÓN 1860-1889 (Millones ptas.)

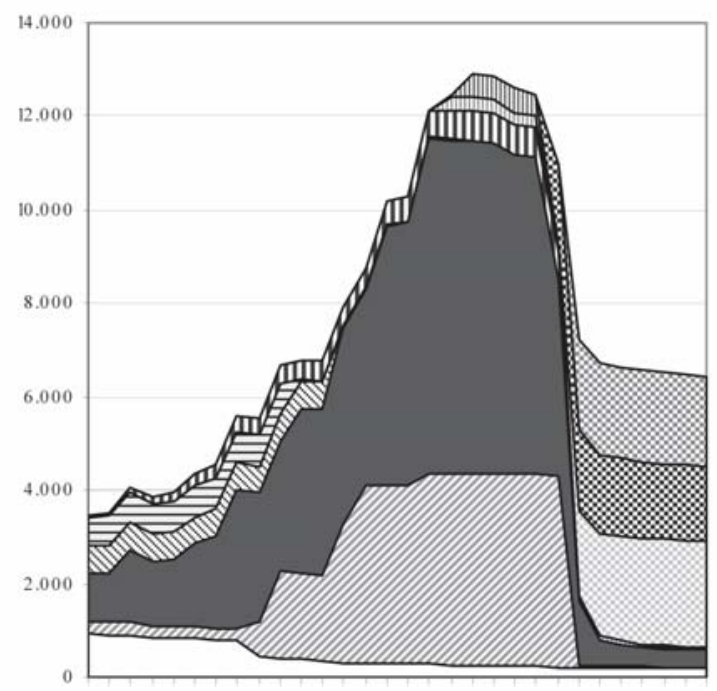

즘 Perpetua del $4 \%$ exterior 즐 Amortizable del $4 \%$ de 1881 $\square$ Perpetua del $4 \%$ interior 미 2\% amortizable interior $\square 2 \%$ amortizable exterior I Obligaciones de ferrocarriles 曰 Diferida del $3 \%$ interior Q Diferida del $3 \%$ exterior 口 $3 \%$ consolidado interior ๑ $3 \%$ consolidado exterior $\square$ Otras

Fuente: Fernández Acha (1976).

En los entresijos de las operaciones, Camacho organizó varias reuniones con representantes del Banco de España y con Bauer. El elemento de acuerdo más difícil e importante fue probablemente que el Banco aceptara convertir todas las letras que tenía pendientes con el Tesoro en el nuevo amortizable ${ }^{86}$, aunque parece claro que la institución salió compensada con las comisiones de colocación y

${ }^{85}$ Véanse Fernández Acha (1976, pp. 711-712), Comín (1996 p. 165) y Broder (1981, p. 616).

${ }^{86}$ Según Tortella (1970, p. 292), este detalle fue muy criticado en el seno del Consejo del Banco. 
la asunción de los derechos para la gestión de los intereses de los títulos. La Casa Rothschild, por su parte, completó su contribución a la conversión con un adelanto de 50 millones en 1881, para financiar el pago de las obligaciones de la serie exterior del Banco y el Tesoro, y otros cuatro créditos a lo largo de 1882, que sumaron 121,5 millones de pesetas. Con ellos el Banco pudo dar suficiente cobertura al pago del nuevo cupón y nutrir con oro y plata sus cámaras para una eventual ampliación del capital, que no se haría esperar ${ }^{87}$.

En conclusión, tras el arreglo la deuda del Tesoro desapareció casi por completo y el nivel medio de la deuda del Estado quedó reducido a un nominal aproximado de 7.000 millones de pesetas, que se mantendría estable hasta la Guerra de Cuba (véanse Gráficos 3 y 4). La carga de intereses anuales de la deuda consolidada, por el contrario, aumentó en 16,5 millones de pesetas. No obstante, este pequeño incremento suponía una ínfima parte de los derechos pendientes de pago de las antiguas partidas de deuda. Empero, indudablemente, el logro más importante consistió en sacar de una vez a la finanzas públicas españolas de su permanente estado de insolvencia y de persistente suspensión de pagos.

\subsection{1: la última gran operación de los Rothschild}

El Banco de España salió muy reforzado de las operaciones de conversión y de una serie de acuerdos con el Gobierno que pondría en sus manos la dirección de la tesorería del Estado y la política monetaria durante el resto del siglo, lo cual le ayudaría a convertirse en el Banco central más rentable de Europa ${ }^{88}$.

Para los Rothschild, en cambio, la evolución fue la contraria. En los siguientes treinta años fueron perdiendo parcelas de negocio en las que, hasta entonces, se habían mostrado intratables, tal y como ocurrió en el ámbito de la financiación del Tesoro o con los suministros de pasta metálica. Las causas que motivaron estos cambios tuvieron un origen complejo. En el primero de los casos parece evidente que fue la estabilidad de las cuentas del Estado español y su renuncia al endeudamiento lo que hizo innecesario el concurso de capitales fuera de la financiación ordinaria o de los servicios del Banco de España. En el segundo, en cambio, la Casa Rothschild perdería mucho peso a causa del hundimiento del precio internacional de la plata, que se llevó por delante a los sistemas bimetálicos, así como por la errática política monetaria adoptada por los primeros gabinetes de la Restauración, con el añadido de la inexistencia de emisiones de deuda que sustentaran las compras de oro y plata ${ }^{89}$. Por lo tanto, hasta fin de siglo el Banco de Espa-

${ }^{87}$ ARL 000/401; Cartas de Bauer de 4 y 7/12/1881, ARL XI/92/0A; y ABE, Secretaría, Legajo 734.

${ }^{88}$ Vid. Anes (1974, p. 161) y Robledo (1988, p. 569-571).

${ }^{89}$ Véase Sardá (reed. 1970, pp. 161-163 y 166). 
ña no adquirió más metal que el necesario para cubrir los encajes que le fue exigiendo la Ley, y las operaciones con los Rothschild quedaron restringidas a dos coyunturas muy puntuales en 1891 y en 1898-1899, en las que el Banco tuvo que aumentar extraordinariamente su capital y reservas.

La primera de ellas coincidió con una crisis financiera internacional aunque, en realidad, las operaciones conjuntas del Banco y del Tesoro de 1891 estuvieron motivadas por desajustes estrictamente internos que venían arrastrándose hacía tiempo. El Banco de España, como consecuencia de los continuos préstamos al Tesoro, había incrementado la circulación de billetes hasta el máximo autorizado por la Ley. Ante la posibilidad de que se pudiera llegar a un estado de paralización en el balance del Banco, el Gobierno aumentó el tope legal de circulación de billetes desde 750 a 1.500 millones de pesetas, con la contrapartida de un "préstamo» de 150 millones, sin abono de intereses, a reintegrar en $1921^{90}$. En relación con esta operación, se llegó a hablar de un préstamo al Tesoro e incluso de una emisión especial de 250 millones de pesetas en títulos amortizables por la Casa Rothschild ${ }^{91}$. Esta última operación se llegó a concretar, pero no estuvo dirigida por la Casa ${ }^{92}$, de manera que su auténtica participación consistió en un préstamo de 50 millones de pesetas al Banco ${ }^{93}$, que constituyó el primero de los plazos de la cesión de 150 millones del Banco al Tesoro y que se completó con varios convenios para adquirir pasta metálica.

Aparte de esta última no se conocen más operaciones relevantes de la Casa Rothschild con el Tesoro o el Banco, salvo su conocida participación en la creación de la Compañía Arrendataria de Tabacos, en $1887^{94}$, y una pequeña venta de oro en 1898, de manera que los Rothschild y su agencia se limitaron a mantener la corresponsalía del Banco de España en París y Londres en lo venidero. Incluso en eso su posición se fue diluyendo a lo largo de los años, ya que el Banco amplió su nómina de corresponsales por toda Europa y, consiguientemente, pudo ir exigiendo cierta competencia en los adelantos y la gestión de pagos y cuentas en el extranjero ${ }^{95}$.

${ }^{90}$ Vid. Tedde y Anes (1974, pp. 131).

${ }^{91}$ Cartas del Embajador de Francia en Madrid a su Ministro de AAEE de 1/9/1891, 19/12/ 1891 y 30/12/1891, Archivo del Ministerio Francés de Economía y Finanzas B-31186.

${ }_{92}$ De acuerdo con Tedde y Anes (1974, p. 135), la agencia tomó sólo 20 millones de pesetas en títulos de la suscripción.

${ }^{93}$ ARL XI-109-121; ABE, Secretaría, legajos 734 y 736, y Operaciones, legajo 61.

${ }^{94}$ La casa Rothschild aportó 6 de los 60 millones de pesetas del capital de la sociedad, colocándose como segundo accionista tras el Banco de España.

${ }^{95}$ En julio de 1889, por ejemplo, el Banco de España escribió a sus corresponsales extranjeros, pidiéndoles información sobre las condiciones de crédito. Se recibieron varias ofertas, incluidas las de las Casas Rothschild de París y Londres, pero éstas últimas fueron rechazadas. ABE, Secretaría, legajo 736. 


\section{TRES PREGUNTAS EN EL AIRE}

\section{1. ¿Cuánto importaron las operaciones de los Rothschild?}

El Gráfico 5 muestra, año por año, la agregación del conjunto de operaciones financieras y comerciales con las instituciones españolas que hemos descrito, excluyendo las ventas de metales preciosos y los adelantos a la Casa Real. En total, desde 1830 a 1900, la Casa Rothschild prestó un total de 764 millones de pesetas al Estado español, a través del Banco de España y del Tesoro Público, colocó emisiones de deuda pública que generaron 306 millones de pesetas líquidas y transfirió un total de 348 millones de pesetas al Estado como beneficio de las ventas del mercurio de Almadén. Puede observarse, por otra parte, una clara multiplicación de las actividades durante los años de la Primera Guerra Carlista y, sobre todo, en el Sexenio Revolucionario y los primeros de la Restauración, en los que se llevan a cabo las mayores transacciones. Con el punto de referencia del déficit presupuestario, puede verse que existe una relación directa entre estas entradas de capital y el desequilibrio en las cuentas de los gobiernos liberales. En este sentido, la interpretación más elemental sería que los capitales aportados por los Rothschild suplieron parcialmente las dificultades de los gobiernos españoles para cubrir sus gastos extraordinarios con recursos nacionales en las épocas de mayor apuro. De la misma manera, queda claro que, una vez que estos desequilibrios se atenuaron gracias a las políticas más contenidas de financiación del gasto y al concurso del Banco de España, los niveles de dependencia del crédito de los banqueros extranjeros fueron bajando y su presencia en las finanzas públicas españolas se hizo menos justificable.

Por otro lado, los casi 700 millones de pesetas en oro y plata que la Casa Rothschild vendió al Banco de España y al Tesoro en la segunda mitad del siglo XIX, fundamentalmente en las décadas de 1860 y 1870, representan un volumen que no podemos dejar de tener en consideración. Es indudable que estas aportaciones fueron muy importantes, en un momento en el que las emisiones de papel y el tejido bancario eran muy débiles en España, y en el que las acuñaciones metálicas continuaban siendo cruciales para la circulación monetaria y los intercambios. Por consiguiente, las entradas masivas de lingotes remesados por los Rothschild habrían ayudado a compensar los desequilibrios de la balanza de pagos, condicionando directamente el volumen de la masa monetaria y ayudando a evitar procesos deflacionarios y la adopción del curso forzoso, que tanto temieron los gobiernos liberales españoles ${ }^{96}$.

${ }^{96}$ La Casa Rothschild siempre opinó que esta medida habría sido muy dañina para los intereses financieros de España, sobre todo tras la experiencia de Italia y Austria. Carta de Alphonse a Lionel Rothschild de 19/10/1869, ARL XI/109/100. 


\section{GRÁFICO 5}

FLUJOS ACUMULADOS DE CAPITAL DE LAS CASAS ROTHSCHILD

HACIA INSTITUCIONES PÚBLICAS ESPAÑOLAS

Y SU RELACIÓN CON EL DÉFICIT, 1830-1900

(Millones ptas.)

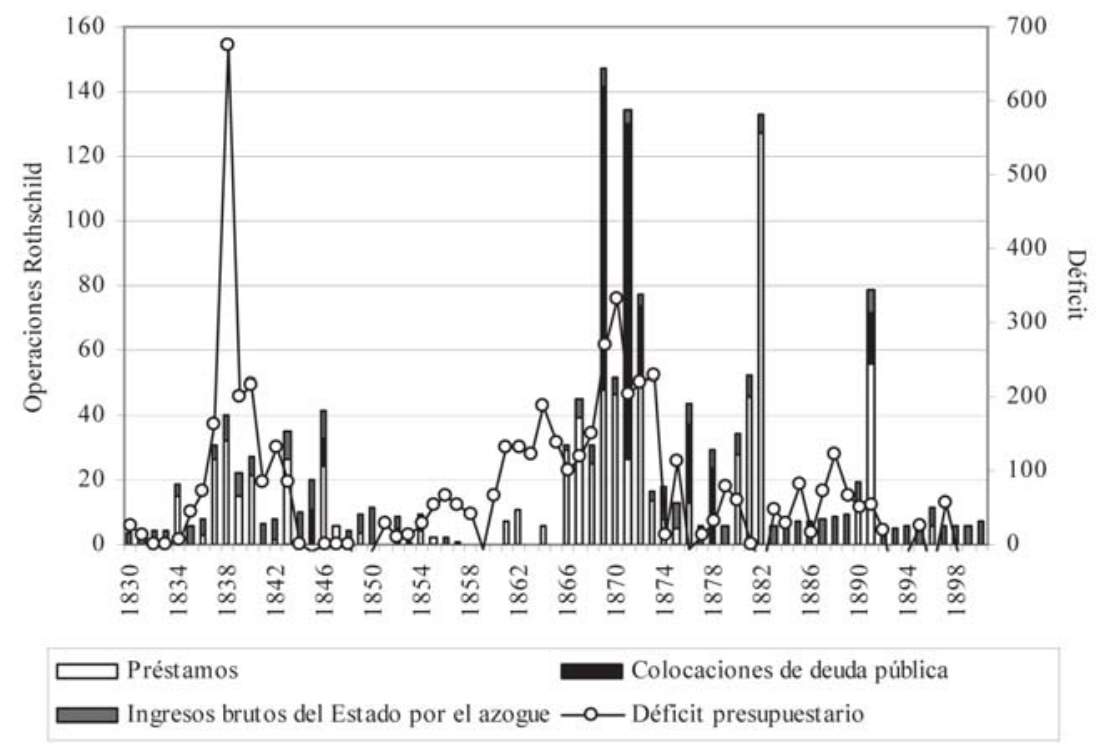

Fuentes: Mismas que los cuadros 1 y A.1.

\section{2. ¿Cuánto costó la aportación de los Rothschild?}

Como no podía ser de otra manera, tanto el Tesoro como el Banco de España tuvieron que abonar intereses por estos servicios, unos servicios que se valoraban en relación directa al riesgo creciente que fueron tomando las iniciativas. La tesis clásica de la historiografía y de algunos analistas contemporáneos dice que las condiciones de los contratos fueron sumamente lesivas a los intereses de la Hacienda. Sin embargo, aun sabiendo que la capacidad de negociación de los sucesivos gobiernos fue menguando desde 1864, un análisis pormenorizado de los contratos muestra que el fenómeno no fue tan terrible como se ha pintado. Como se observa en el Gráfico 7, el coste de las operaciones de los Rothschild apenas difiere de los precios vigentes en el mercado en los primeros años de la muestra. A partir de 1866, en cambio, el mercado español de capitales se polariza y empieza a operar un precio del dinero para el mercado ordinario -descuento 


\section{GRÁFICO 6 \\ VENTAS DE ORO Y PLATA DE LOS ROTHSCHILD AL TESORO Y AL BANCO DE ESPAÑA EN RELACIÓN A LAS ACUÑACIONES NETAS DE MONEDA Y LOS INCREMENTOS EN LA OFERTA MONETARIA, 1860-1875 \\ (Millones ptas).}

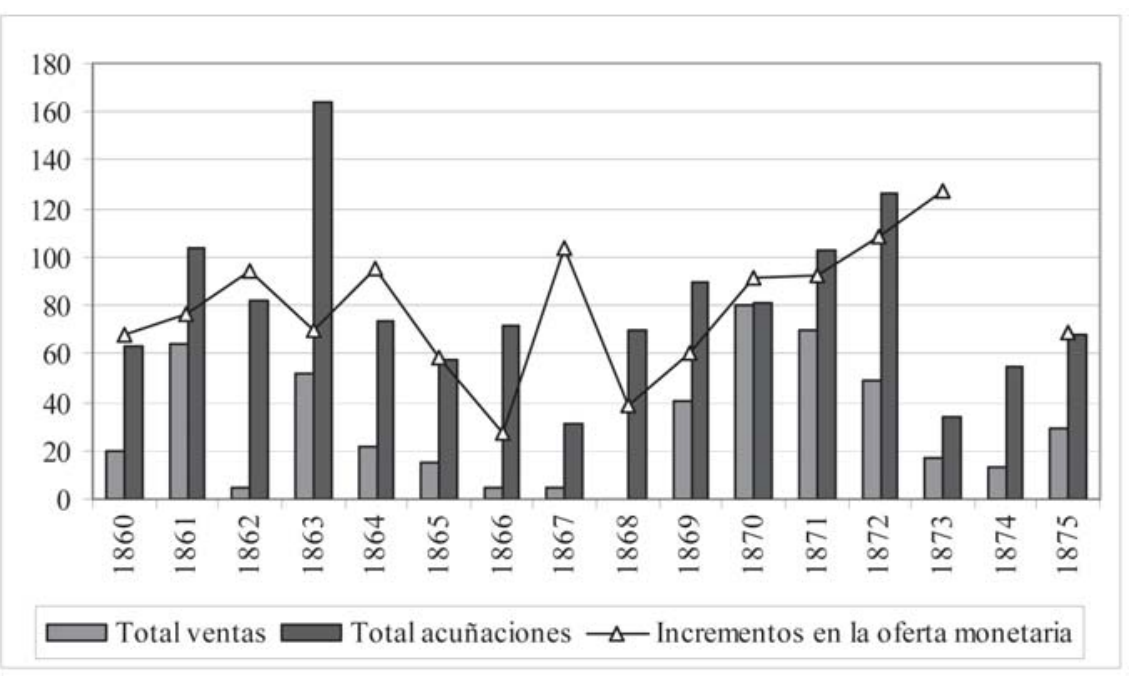

Fuentes: García Patón (1903, p. 86), Sardá (1970, pp. 333-342), Tortella (1974, p. 120), García Ruiz (1996) y Apéndice A.1.

Nota: 1874 ha sido excluido de la serie «incrementos en la oferta monetaria» por presentar un fuerte hundimiento negativo en la fuente original.

oficial- mucho más barato que el que realmente estaba abonando el Tesoro a sus prestamistas ocasionales. No tenemos una serie de los intereses de la deuda flotante para esos años, pero las cifras que hemos ido indicando confirman que el interés medio de estas operaciones seguía, en el mejor de los casos, la estela de la tasa de rendimiento neto -o tipo de interés efectivo- de la deuda consolida. En ese ámbito, no podemos obviar el hecho de que la Casa Rothschild llegaba a ofrecer no menos de cuatro puntos por debajo de las condiciones de la competencia en los momentos más críticos. Bajo estas premisas, no creemos que puedan ser consideradas como usurarias o «leoninas» las condiciones a las que se tomaron la mayor parte de las operaciones, sino básicamente condicionadas por la coyuntura. Aunque resulte sorprendente, su concurso casi siempre resultaba la opción más barata a la hora de llevar adelante la mayor parte de las operaciones, lo que explicaría la continuidad de los contactos con unas instituciones públicas que, no 
lo olvidemos, buscaban la línea más eficiente en la captación de capitales. Por añadidura, los Rothschild mostraron gran habilidad para calibrar el riesgo de las operaciones y para reducirlo, cruzando operaciones clásicas de crédito con otros negocios de la Casa en España, como el del mercurio, la venta de metales o el ferrocarril. Es muy significativo que los Rothschild nunca dejaran de cobrar sus servicios al Estado.

Ocurría prácticamente lo mismo en el mercado de metales preciosos, íntimamente vinculado a las operaciones de tesorería del Gobierno, a las necesidades monetarias del país y a los requerimientos del Banco de España para potenciar sus reservas. Un análisis muy elemental de los precios que aplicaron los Rothschild a sus ventas de oro en España demuestra que la rentabilidad de estas operaciones para ellos era, en el mejor de los casos, cercana al uno por cien, a fuerza de sacar partido de las reducciones de costes de sus propias fundiciones, que ofrecían oro de refundición ligeramente más barato que el mercado libre. Este margen tan estrecho no cuenta los costes de transporte, embalaje, seguro y corretaje, que estaban incluidos en el precio final, por lo que el beneficio sólo podía ser significativo si se llevaba a cabo una importante cantidad de intercambios. La Casa de la Moneda española, en cambio, acuñaba a 900 milésimas el oro que los Rothschild le vendían a 1.000 milésimas -oro fino de 24 quilates-, por lo que podía obtener de inicio hasta un 10 por cien bruto de esas compras.

\section{3. ¿Qué papel desempeñaron las compensaciones indirectas?}

Un último elemento que no hemos nombrado hasta ahora, pero en el que la historiografía ha insistido especialmente, es el de las «compensaciones indirectas». Este término, acuñado por Jordi $\mathrm{Nadal}^{97}$, viene a expresar que, gracias a su capacidad de negociación frente a los inestables gobiernos liberales, los inversores extranjeros buscaron, exigieron y consiguieron facilidades extraordinarias para sus inversiones en España, con especial protagonismo de los Rothschild, los cuales habrían aprovechado su posición frente a sus autoridades para hacerse con el monopolio de las ventas de productos de Almadén, conseguir privilegios para su compañía ferroviaria y facilidades para levantar grandes emporios mineros, como Riotinto y Peñarroya.

El argumento sería, en principio, correcto, pero no tanto la relación de causalidad aplicada, que no siempre se extrae de una contrastación de los fondos documentales originales.

\footnotetext{
97 Nadal (1975, pp. 33-34). El concepto, aunque con matices, ha cobrado peso entre afamados autores. Entre otros, Comín (1988, pp. 372-373 y 429) y (1995, pp. 74-75) o García Delgado y Jiménez (1999 p. 14).
} 


\section{GRÁFICO 7 \\ TIPOS DE INTERÉS DE LOS CRÉDITOS DE LOS ROTHSCHILD \\ A INSTITUCIONES PÚBLICAS ESPAÑOLAS, CON RELACIÓN \\ A OTROS TIPOS DE REFERENCIA \\ (1860-1900)}

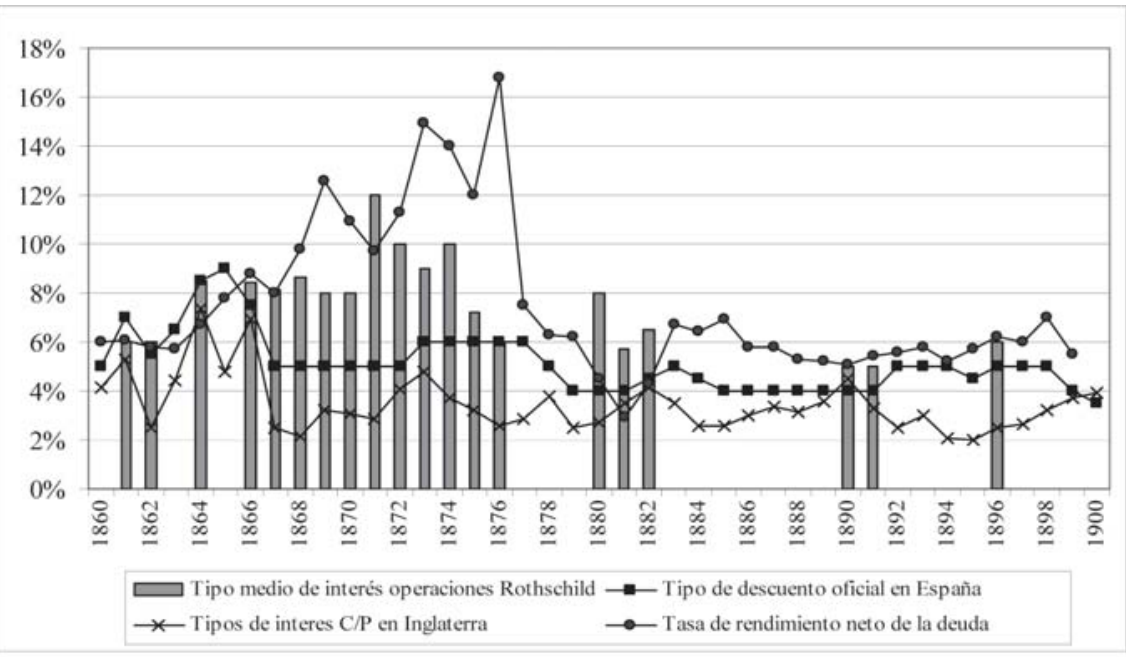

Fuentes: García Ruiz (1996, pp. 245-246), Tafunell (1989, pp. 481-482) y Homer y Sylla (1991).

En el caso del ferrocarril ya hemos intentado demostrar en otro lugar que no existieron conexiones entre los proyectos de los Rothschild y la gestación de la legislación ferroviaria y bancaria de 1855 y $1856^{98}$; aunque, como ya hemos indicado, sí hubo un interés por buscar compensaciones a la falta de rentabilidad de su empresa ferroviaria a partir de la crisis de 1864. Tampoco hubo intervención en la venta de las minas de Riotinto ni en el desarrollo posterior de la Sociedad Minera y Metalúrgica de Peñarroya ${ }^{99}$. Quedan, por otra parte, bastantes dudas de que el boom minero español fuese consecuencia de la Ley de Bases de 1868, y más bien parece vinculado a un incremento de la demanda europea y norteamericana de fines del siglo XIX, que ya había generado importantes iniciativas como la compañía de Tharsis o la Asturiana de Minas anteriores a la Ley. Resta, por

\footnotetext{
${ }^{98}$ López-Morell (1999b).

99 Véase López-Morell (1999a y 2003).
} 
tanto, la vía clásica, constantemente repetida, del monopolio de las ventas del mercurio de Almadén y su mantenimiento en el tiempo por los Rothschild como paradigma de las compensaciones.

Se argumenta que la obtención de este monopolio, del que disfrutaron los Rothschild casi sin interrupción desde 1830 hasta 1921, fue fruto del chantaje continuo de la familia de banqueros al Estado español para asegurar la continuidad de sus préstamos de los que tanto dependía, lo cual es cierto. Siguiendo este argumento, los contratos firmados habrían privado al Estado de un beneficio considerable y le habrían obligado, por añadidura, a remunerar espléndidamente a los banqueros judíos por treinta años, tras el famoso préstamo de $1870^{100}$. Sin embargo, hay que hacer una serie de matizaciones tanto sobre la naturaleza y las consecuencias de tan polémico acuerdo como del desarrollo general de la cesión de las ventas.

En primer lugar, es necesario insistir en que el préstamo aludido no fue exactamente una imposición o una propuesta de los banqueros, sino que fue el propio Figuerola el que rogó a los Rothschild que le multiplicaran considerablemente los adelantos sobre la cuenta de ventas de los productos de Almadén o que incluso se pensaran la posibilidad de comprar las propias minas. A los banqueros no les pareció conveniente lo segundo, pero no les importó negociar la concesión de nuevos créditos hasta concluir en el préstamo de abril de 1870, que fue más reducido que lo que hubiera deseado el Ministro ${ }^{101}$. Por otra parte, como puede observase en el Gráfico 8, a lo largo de los treinta años del contrato el Estado recibió en torno al 80 por cien del beneficio del mercurio. Si a esta cantidad le detraemos los pagos del préstamo, 121.138 .500 pesetas $^{102}$, el Tesoro pudo obtener un porcentaje de beneficio en el reparto que siguió casi doblando al que recibieron los Rothschild -63.714.709 frente a 36.330.572 pesetas-, con lo que no cabe duda de que el Gobierno español compartió los beneficios del monopolio de la oferta que levantaron los Rothschild y para el cual no demostró capacidad en las coyunturas de 1821 a 1830, 1847-1848 e incluso 1857-1865, en los que se hizo cargo de la comercialización con menores beneficios. No cabe duda, por otra parte, de que existió un agravio en los contratos de 1835 a 1843, en los cuales los banqueros prácticamente igualaron el beneficio del Estado, gracias en parte a corruptelas promovidas por ellos, lo que demuestra que el sistema de venta a comisión, posterior a 1870, era mucho más adecuado que las subastas. Lo anterior no excluye que el Tesoro se hubiera beneficiado también en esos años de las ventajas del monopolio.

\footnotetext{
${ }^{100}$ Nadal (1975, pp. 109-115).

101 Cartas de Weisweiller y Bauer de 18, 19 y 27/3/1869 y 5/4/1869, ARL XI/ 109/101.

102 Según Martín (1980, cap. 7). Tortella (1981, p. 60), calcula un interés real del 15 por cien anual a la operación.
} 
Por otra parte, ni los contemporáneos ni el propio Nadal apreciaron que los Rothschild tomaron una prima de riesgo altísima al firmar un contrato a tan largo plazo como el de 1870. Según los informes que recibieron de sus agentes, el mercado se encontraba por esas fechas en una situación nada halagüeña, con un estancamiento generalizado en las ventas de azogues en Méjico ${ }^{103}$ y un enfriamiento general de los intercambios en Europa. Por otro lado, tampoco parece que se haya tenido en cuenta que el futuro de las ventas estaba a expensas de cualquier cambio tecnológico que viniera a excluir a corto plazo al mercurio de muchos procesos industriales. No obstante, y a decir verdad, los Rothschild demostraron su experiencia emitiendo un empréstito hipotecario paralelo al préstamo, por lo que compensaron los peligros de la operación diversificando el riesgo en el largo plazo ${ }^{104}$.

\section{GRÁFICO 8 \\ BENEFICIOS REPARTIDOS POR LAS VENTAS \\ DEL MERCURIO DE ALMADÉN, 1830-1921}

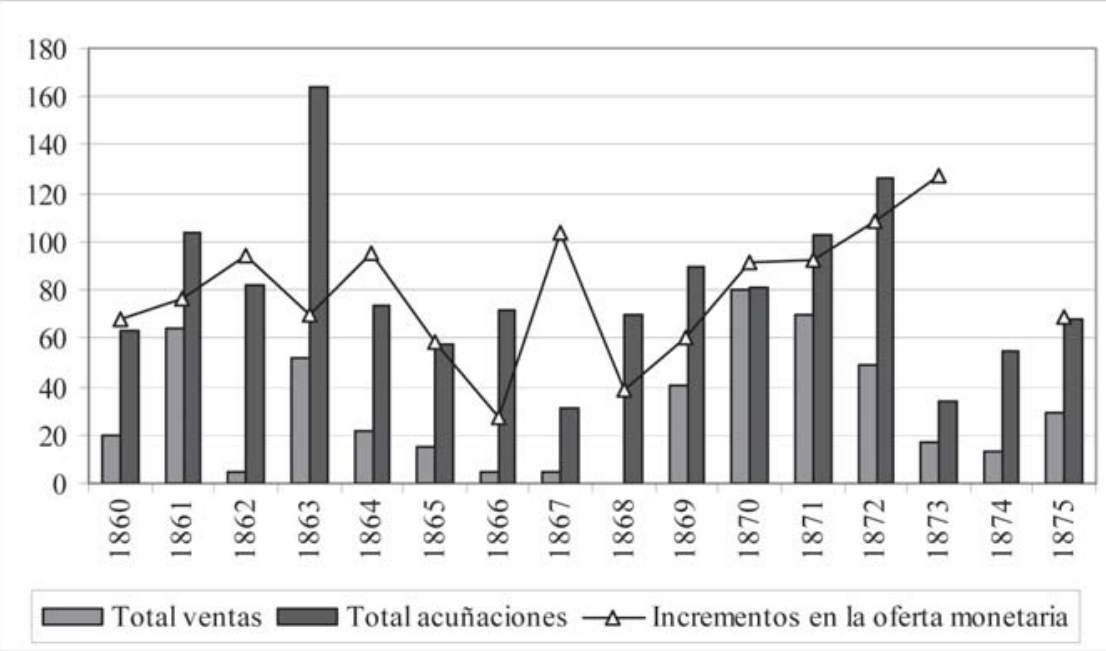

Fuente: Martín (1980), Roldán (2003) y ARL VII/15/0-2 Quicksilver account, num. 2.

\footnotetext{
${ }^{103}$ Carta de 28/4/1869 de José $M^{a}$ V. y Baz desde México, en nombre de N. Davidson. ARL, XI/109/98.

${ }^{104}$ Los aspectos específicos de la operación pueden encontrarse en Martín (1980, capítulo 7).
} 


\section{CONCLUSIONES}

La larga presencia de la Casa Rothschild en España durante el siglo XIX pone sobre la mesa algunas de las carencias más significativas de las finanzas públicas españolas, en las cuales la falta de una política fiscal coherente y el desbarajuste en la política de financiación derivó en una absurda vorágine de endeudamiento.

La clave para entender este fenómeno estuvo en la errática evolución política, que se caracterizó por la falta de planes operativos a largo plazo que ayudaran a estabilizar las cuentas del Estado. En consecuencia, los sucesivos gobiernos fueron desarrollando un modelo de financiación desordenado, en el que primaron las urgencias y la escasa eficiencia en las operaciones de endeudamiento. Los Rothschild fueron unos de los principales sostenedores de este sistema, en el que ejercieron como intermediarios privilegiados frente a los mercados internacionales de capital. En este ámbito, los Rothschild aprovecharon su posición predominante para obtener rentas extraordinarias y privilegios en otros negocios, pero también aportaron mayor eficiencia que otros grupos bancarios y un coste más contenido en las operaciones, lo que aseguró la continuidad de sus contactos con el Tesoro y el Banco de España.

El altísimo coste de oportunidad que tuvo que pagar la economía española por el despilfarro que suponía mantener este esquema de financiación fue, sin duda, perjudicial para el desarrollo, por la excesiva remuneración de estos capitales frente a otras inversiones productivas; lo que da pleno sentido a la metáfora de «el capital tirado por la borda», acuñada por Cameron (1971, cap. 13). No obstante, si queremos destacar algún aspecto positivo de este proceso, podemos indicar que su intervención ayudó a consolidar el proceso de cambio político hacia el liberalismo y también compensó en parte los errores de la política monetaria de los gobiernos españoles, lo cual evitó la aparición de fenómenos deflacionistas en las décadas centrales del siglo. Por otra parte, la experiencia traumática de los arreglos y suspensiones de pagos obligó a las autoridades económicas españolas a un proceso de aprendizaje en el que, paulatinamente, fueron ensayando formas de financiación más consistentes, baratas e independientes de los flujos de capital extranjero.

\section{FUENTES}

Archives Banque Rothschild Frères (ARP). Centre des Archives du Monde du Travail, Roubaix (Francia). Serie 132AQ, dossiers: 1, 2, 24-27, 30, 40, 41, 80, 85, 86, 103-109, 116, 117, 128, 139, 322, 335, 337, 338, 342, 343, 354, 722-747 у 6136-6274.

Rothschild Archives London (ARL), Londres: Section 000 (Boxes 89, 374, 401, 474), Account Department (I) (Boxes 0, 1 y 52), Book Keeping Department (VI) (Boxes 11 y 12), Bullion Department (VII) (Boxes 10 y 15), Correspondence Department 
XI (Boxes 4, 15, 33, 92, 109, 110, 111 y 112) y Family Archive (RfamFP/5/7 y $\mathrm{RfamFD/5).}$

Archivo del Banco de España (ABE), Madrid. Sección Secretaría: Legajos 733, 736, 740, 741, 789, 1138, 1196, 1197, 1200-1202, 1206-1218, 1224, 1259, 1260, 1262,1263 у 3820 y Cajas: 706, 993, 1013-1015, 1022, 1023, 1144, 1145, 1147, 1148 y 1150. Sección Operaciones: Legajos: 61 y 125.

Archives du Ministère Français des Affaires Etrangères, París: Affaires commerciales divers: 288; Correspondance Politique. España: 848; Correspondance Commercial, Madrid: 44; Europe 18-29. Espagne: 105 y 110; Europe 18-40. Espagne: 81, 87, 112-114, 116, 254 y 255; Nouvelle Série. Espagne: 56, 61, 63, 73, 85, 87 y 88; Relations Commerciales 20-40; Série Y Internationale 18-40: 321; Série Y Internationale Espagne: 110.

Archives du Ministère de Economie et Finances, París (série B): 31181, 31186, 31188, 31189, 31193, 31194, 31201, 31202, 32000, 32835, 33238 у 32841.

Archivo del Congreso de los Diputados, Madrid: Serie General, legajo 131; serie impresos: legajo 5.

\section{BIBLIOGRAFÍA}

ANEs, R. (1974): «El Banco de España (1874-1914), un banco nacional», en G. Tortella (ed.), La Banca Española en la Restauración. Madrid: Banco de España. Vol. I, pp. 107-216.

Artola, M. (1986): La Hacienda del Siglo XIX. Progresistas y Moderados. Madrid: Alianza. Bouvier, J. (1967): Les Rothschild. París : Fayard.

Broder, A. (1981): Le role des interêts étrangers dans la croissance économique de l'Espagne: 1815 -1913. Etat, entreprise et histoire. París : Université de Paris X. Microficha.

Calavera, A. (1991): «La casa Rothschild, Madrid y La Habana y operaciones financieras y tabaco». Arbor n ${ }^{\circ}$ 547-548, pp. 181-196.

CAmeron, R. (1971): Francia y el desarrollo económico de Europa, 1800-1914. Madrid: Tecnos.

Chapman, S. (1984): The rise of the Merchant Banking. Londres: Unwin Hyman.

Carrera Raya, F. (1987): Antecedentes Histórico-Jurídicos de la Deuda Pública Española. Málaga: Universidad de Málaga.

Сомín, F. (1988): Hacienda y economía en la España contemporánea (1800-1936). Madrid: Instituto de Estudios Fiscales.

- (1989): «El Sector Público», en A. Carreras (ed.), Estadísticas históricas de España. Siglos XIX y XX. Madrid: Fundación Banco Exterior, pp. 397-460.

- (1996): Historia de la Hacienda Pública, II. España 1808-1995. Barcelona: Crítica.

CoRTI, C. (1928): The Rise of House Rothschild. Londres: Victor Gollancz Ltd.

Dobado, R. (1997): «Las minas de Almadén, el monopolio del azogue y la producción de plata en Nueva España en el siglo XVIII», en J.O. Sánchez, G. Mira y R. Dobado, $L a$ savia del Imperio. Tres estudios de economía colonial. Salamanca: Ediciones de la Universidad, pp. 403-495. 
Documentos relativos al arreglo general de la deuda del Estado (1851) Madrid: Imprenta Nacional.

EsTAPÉ, F. (1971) La reforma tributaria de 1841: estudio preliminar y consideración de sus precedentes inmediatos. Madrid: Ministerio de Hacienda, Instituto de Estudios Fiscales.

Ferguson, N. (1998): The World's Banker. The History of the House of Rothschild. Londres: Weidenfeld \& Nicolson.

Fernández Acha, V. (1976): La deuda pública, volumen II de Datos básicos para la historia financiera de España, 1850/1875. Madrid: Ministerio de Hacienda. Instituto de Estudios Fiscales.

Flores, M. (1981): La venta de las minas de Río Tinto. Huelva: Diputación Provincial.

FontanA, J. (1973): Hacienda y Estado, 1823-1833. Madrid: Instituto de Estudios Fiscales.

- (1974): La quiebra de la monarquía absoluta, 1814-1820. Madrid: Instituto de Estudios Fiscales.

— (1977): La Revolución Liberal. Política y Hacienda en 1833-1845. Madrid: Instituto de Estudios Fiscales.

García Delgado, J. L. y JimÉNez, J. C. (1999): «El proceso de modernización económica: perspectiva histórica y comparada», en J.L. García Delgado (ed.), España, economía: ante el siglo XXI. Madrid: Espasa, pp. 7-30.

García Ratón, F. (1903): La Fabricación de Monedas. Madrid: Tipografía de J. Benito Cerezo.

García Ruiz, J. L. (1996): «Moneda y Finanzas en España, 1845-1921», en J. Hernández Andreu (coord.), Historia monetaria y financiera de España. Madrid: Síntesis, pp. 123188.

Gille, B. (1965, 1967): Histoire de la Maison Rothschild. Ginebra-París: Librairie Droz

Gonzalo González, L. (1981): El Tesoro Público y la Caja General de Depósitos (18521868). Madrid: Instituto de Estudios Fiscales.

Homer, S. y Sylla, R. (1991): A history of interest rates. New Brunswick \& Londres: Rutgers University Press.

JANKE, P. (1974): Mendizábal y la instauración de la monarquía constitucional en España (1790-1853). Madrid: Siglo XXI.

López-Morell, M. (1999a): «Propiedad y control en la gran minería andaluza: los Rothschild en Peñarroya y Río Tinto», en A. Parejo y A. Sánchez Picón (eds), Economía Andaluza e Historia Industrial. Estudios en Homenaje a Jordi Nadal. Motril: Azucaría Mediterránea Ediciones, pp. 245-262.

- (1999b): «El papel de los Rothschild en la construcción de los ferrocarriles en España (1855-1874)», en M. Muñoz, J. Sanz y J. Vidal (eds.), Siglo y medio de ferrocarril en España, 1848-1998. Economía, industria y sociedad. Madrid: Fundación Ferrocarriles Españoles. pp. 669-692.

— (2003): «Peñarroya: un modelo expansivo de corporación minero-industrial, 1881-1936». Revista de Historia Industrial 23, pp. 95-134.

MARCHAL, C. (1980): La revolución liberal y los primeros partidos políticos en España, 1834-1844. Madrid: Cátedra.

Martín Martín, V. (1980): Los Rothschild y las minas de Almadén: el servicio de la deuda pública española y la comercialización del mercurio de Almadén. Madrid: Instituto de Estudios Fiscales. 
Martín Niño, J. (1972): La Hacienda Española y la Revolución de 1868. Madrid: Instituto de Estudios Fiscales.

Miraflores, Marqués DE (1964) [reedición de varios textos escritos entre 1843 y 1873]: Memorias del reinado de Isabel II. Madrid: Atlas, Biblioteca de Autores Españoles.

NADAL, J. (1975): El fracaso de la Revolución Industrial en España, 1814-1913. Barcelona: Ariel.

Otazu, A. (1987): Los Rothschild y sus socios españoles (1820-1850). Madrid: OHS.

Randall, R. W. (1977): Real Del Monte: una empresa británica en México. México-Madrid-Buenos Aires: Fondo de Cultura Económica.

Robledo, R. (1988): «¿Quiénes eran los accionistas del Banco de España?». Revista de Historia Económica VI (3), pp. 557-591.

RoldÁn de Montaud, I. (1997): «Guerra y finanzas en la crisis de fin de siglo: 1895-1900». Hispania LVII/2 (196), pp. 611-675.

- (2003): «Los intereses de los banqueros británicos en España: la Banca Baring y su pugna con los Rothschild por el control del mercurio de Almadén», Hispania LXIII/1 (213), pp. 255-293.

SAiz PASTOR, C. (1991): «La revolución liberal española y el control de la hacienda cubana (1826-1843)». Revista de Historia Económica IX (2), pp. 341-360.

SÁnchez Albornoz, N. (1968): España hace un siglo: una economía dual. Madrid: Alianza. SÁnChEZ Molero, L. (1859): Memoria sobre azogues. Madrid: Imprenta de la viuda de A. Yenes.

SÁnchez Ocaña, J. (1855) Reseña histórica sobre el estado de la Hacienda y del Tesoro Público en España durante las administraciones progresista y moderada y sobre el origen e importe de la actual deuda flotante del mismo Tesoro. Madrid: Imprenta de Tejado.

Santillán, R. (1960) [reed.]: Memorias (1815-1856). Pamplona: Studium Generale, 2 vols.

SARDÁ, J. (1970) [1948]: La política monetaria y la fluctuaciones de la economía española en el siglo XIX. Barcelona: Ariel.

TAfunell, X. (1989): «Asociación mercantil y bolsa», en A. Carreras (ed.), Estadísticas históricas de España. Siglos XIX y XX. Madrid: Fundación Banco Exterior, pp. 463494.

Tedde, P. (1981): «El gasto público en España, 1875-1906: un análisis comparativo con las economías europeas». Hacienda Pública Española 69, pp. 237-265.

- (1999): El Banco de San Fernando (1829-1856). Madrid: Alianza/Banco de España.

Tedde, P. y Anes, R. (1974): «La caída de la Casa Baring y la economía española a finales del siglo XIX». Hacienda Pública Española 27, pp. 115-136.

Tortella, G. (1970): «El Banco de España entre 1829-1929. La formación de un Banco Central», en El Banco de España. Una Historia Económica. Madrid: Servicio de Estudios del Banco de España, pp. 261 a 313.

- (1973): Los orígenes del capitalismo en España. Banca, industria y ferrocarriles en el S. XIX. Madrid: Tecnos.

— (1974): «Estimación del «stock» de oro en España (1874-1914)», en G. Tortella (ed.), La Banca Española en la Restauración. Madrid: Banco de España, pp.119-139.

- (1981): «La economía española. 1830-1900», en M. Muñón de Lara (dir.) Historia de España, Barcelona: Labor, Tomo VIII, pp.11-167. 
APÉNDICE

CUADRO A-1

OPERACIONES FINANCIERAS Y COMERCIALES DE

LA CASA ROTHSCHILD CON INSTITUCIONES PÚBLICAS ESPAÑOLA, 1834-1900. AGREGADOS ANUALES. (pesetas corrientes)

\begin{tabular}{|l|c|c|c|c|c|c|}
\hline Año & $\begin{array}{c}\text { Préstamos } \\
\text { a corto } \\
\text { plazo* }\end{array}$ & $\begin{array}{c}\text { Adelantos } \\
\text { a la } \\
\text { Casa Real }\end{array}$ & $\begin{array}{c}\text { Préstamos } \\
\text { a largo } \\
\text { plazo* }\end{array}$ & $\begin{array}{c}\text { Operacio- } \\
\text { nes con } \\
\text { deuda* }\end{array}$ & $\begin{array}{c}\text { Ingresos del } \\
\text { Estado por } \\
\text { azogue** }\end{array}$ & $\begin{array}{c}\text { Ventas } \\
\text { de oro y } \\
\text { plata* }\end{array}$ \\
\hline 1830 & - & - & - & - & 3.743 .998 & - \\
\hline 1831 & - & - & - & - & 3.757 .856 & - \\
\hline 1832 & - & - & - & - & 4.112 .584 & - \\
\hline 1833 & - & - & - & - & 4.105 .553 & - \\
\hline 1834 & 14.718 .750 & - & - & - & 4.104 .199 & - \\
\hline 1835 & - & - & - & - & 5.859 .149 & - \\
\hline 1836 & 2.561 .000 & - & - & - & 5.652 .812 & - \\
\hline 1837 & 8.625 .000 & 5.083 .333 & 12.500 .000 & - & 4.755 .135 & - \\
\hline 1838 & 23.625 .000 & 8.750 .000 & - & - & 7.462 .125 & - \\
\hline 1839 & 12.683 .535 & 2.500 .000 & - & - & 6.928 .650 & - \\
\hline 1840 & 21.500 .000 & 250.000 & - & - & 5.619 .375 & - \\
\hline 1841 & - & - & - & - & 6.162 .075 & - \\
\hline 1842 & 1.758 .000 & - & - & - & 6.230 .925 & - \\
\hline 1843 & 13.950 .000 & - & 12.500 .000 & - & 8.474 .370 & - \\
\hline 1844 & 1.437 .500 & - & - & - & 8.767 .464 & - \\
\hline 1845 & - & - & - & 10.833 .333 & 9.222 .234 & - \\
\hline 1846 & 16.030 .073 & 8.250 .000 & - & 8.333 .333 & 9.167 .833 & - \\
\hline 1847 & 5.754 .000 & - & - & - & & - \\
\hline 1848 & 1.672 .140 & - & - & - & 3.020 .640 & - \\
\hline 1849 & 3.595 .132 & - & - & - & 7.486 .982 & - \\
\hline 1850 & - & - & - & - & 11.754 .750 & - \\
\hline 1851 & - & - & - & - & - & - \\
\hline 1852 & 4.836 .000 & - & - & - & 3.395 .764 & 2.901 .600 \\
\hline 1853 & 832.500 & - & - & - & - & 9.400 .000 \\
\hline 1854 & 4.375 .000 & - & - & - & 4.775 .508 & - \\
\hline
\end{tabular}


CUADRO A-1 (continuación)

OPERACIONES FINANCIERAS Y COMERCIALES DE

LA CASA ROTHSCHILD CON INSTITUCIONES PÚBLICAS ESPAÑOLA, 1834-1900. AGREGADOS ANUALES. (pesetas corrientes)

\begin{tabular}{|c|c|c|c|c|c|c|}
\hline Año & $\begin{array}{c}\text { Préstamos } \\
\text { a corto } \\
\text { plazo* }\end{array}$ & $\begin{array}{c}\text { Adelantos } \\
\text { a la } \\
\text { Casa Real }\end{array}$ & $\begin{array}{c}\text { Préstamos } \\
\text { a largo } \\
\text { plazo* }\end{array}$ & $\begin{array}{c}\text { Operacio- } \\
\text { nes con } \\
\text { deuda* }\end{array}$ & $\begin{array}{c}\text { Ingresos del } \\
\text { Estado por } \\
\text { azogu*** }\end{array}$ & $\begin{array}{c}\text { Ventas } \\
\text { de oro y } \\
\text { plata* }\end{array}$ \\
\hline 1855 & 1.962 .995 & - & - & - & - & - \\
\hline 1856 & - & - & - & - & 2.218 .352 & - \\
\hline 1857 & - & - & - & - & 1.011 .635 & - \\
\hline 1858 & - & - & - & - & - & - \\
\hline 1859 & - & - & - & - & - & - \\
\hline 1860 & - & - & - & - & - & 19.950 .000 \\
\hline 1861 & 7.200 .000 & - & - & - & - & 63.694 .278 \\
\hline 1862 & 10.450 .000 & - & - & - & - & 14.250 .000 \\
\hline 1863 & - & - & - & - & - & 52.250 .000 \\
\hline 1864 & 5.700 .000 & - & - & - & - & 21.850 .000 \\
\hline 1865 & - & - & - & - & - & 14.837 .928 \\
\hline 1866 & 29.140 .000 & - & - & - & 1.578 .229 & 4.789 .979 \\
\hline 1867 & 39.600 .000 & - & - & - & 5.744 .841 & 14.250 .000 \\
\hline 1868 & 24.903 .000 & - & - & - & 5.824 .354 & - \\
\hline 1869 & 48.190 .871 & - & - & 93.548 .200 & 5.577 .829 & 40.591 .300 \\
\hline 1870 & 4.270 .440 & - & 42.419 .038 & - & 4.631 .358 & 78.570 .000 \\
\hline 1871 & 26.131 .050 & - & - & 104.079 .835 & 4.380 .616 & 70.485 .487 \\
\hline 1872 & 48.905 .400 & - & - & 24.937 .500 & 2.952 .327 & 49.892 .666 \\
\hline 1873 & 13.799 .890 & - & - & - & 2.424 .506 & 16.762 .096 \\
\hline 1874 & 7.864 .000 & - & - & - & 9.859 .863 & 13.314 .175 \\
\hline 1875 & 5.148 .000 & - & - & - & 7.934 .060 & 29.279 .833 \\
\hline 1876 & 12.658 .500 & - & - & 24.600 .000 & 6.408 .742 & - \\
\hline 1877 & - & - & - & - & 5.856 .207 & 8.595 .458 \\
\hline 1878 & - & - & - & 23.750 .000 & 5.842 .121 & - \\
\hline 1879 & - & - & - & - & 5.851 .773 & 6.613 .613 \\
\hline 1880 & 27.900 .000 & - & - & - & 6.469 .805 & 5.037 .725 \\
\hline
\end{tabular}


CUADRO A-1 (continuación)

OPERACIONES FINANCIERAS Y COMERCIALES DE

LA CASA ROTHSCHILD CON INSTITUCIONES PÚBLICAS ESPAÑOLA, 1834-1900. AGREGADOS ANUALES. (pesetas corrientes)

\begin{tabular}{|c|c|c|c|c|c|c|}
\hline Año & $\begin{array}{c}\text { Préstamos } \\
\text { a corto } \\
\text { plazo* }\end{array}$ & $\begin{array}{l}\text { Adelantos } \\
\text { a la } \\
\text { Casa Real }\end{array}$ & $\begin{array}{c}\text { Préstamos } \\
\text { a largo } \\
\text { plazo* }\end{array}$ & $\begin{array}{c}\text { Operacio- } \\
\text { nes con } \\
\text { deuda* }\end{array}$ & $\begin{array}{c}\text { Ingresos del } \\
\text { Estado por } \\
\text { el azogue } * *\end{array}$ & $\begin{array}{c}\text { Ventas } \\
\text { de oro y } \\
\text { plata* }\end{array}$ \\
\hline 1881 & 46.000 .000 & - & - & - & 6.280 .123 & - \\
\hline 1882 & 126.985 .000 & - & - & - & 5.957 .820 & 20.180 .881 \\
\hline 1883 & - & - & - & - & 5.796 .890 & 8.490 .974 \\
\hline 1884 & - & - & - & - & 5.382 .666 & - \\
\hline 1885 & - & - & - & - & 6.832 .640 & - \\
\hline 1886 & - & - & - & - & 7.243 .205 & - \\
\hline 1887 & - & - & - & - & 8.098 .977 & - \\
\hline 1888 & - & - & - & - & 8.380 .589 & 4.100 .686 \\
\hline 1889 & - & - & - & - & 9.033 .615 & 5.199 .300 \\
\hline 1890 & 10.700 .000 & - & - & - & 8.897 .610 & 10.449 .595 \\
\hline 1891 & 55.500 .000 & - & - & 16.200 .000 & 7.028 .965 & 55.997 .746 \\
\hline 1892 & - & - & - & - & 5.006 .783 & 16.739 .549 \\
\hline 1893 & - & - & - & - & 4.792 .785 & - \\
\hline 1894 & - & - & - & - & 5.708 .556 & - \\
\hline 1895 & - & - & - & - & 5.015 .164 & - \\
\hline 1896 & 6.050 .000 & - & - & - & 5.203 .816 & - \\
\hline 1897 & - & - & - & - & 5.630 .339 & - \\
\hline 1898 & - & - & - & - & 6.031 .449 & 24.165 .444 \\
\hline 1899 & - & - & - & - & 5.919 .840 & 12.654 .782 \\
\hline 1900 & - & - & - & - & 7.090 .789 & - \\
\hline Total & 697.012 .776 & 24.833.333 & 67.419 .038 & 306.282 .201 & 348.459 .222 & 695.295 .094 \\
\hline
\end{tabular}

Fuentes: ARL, series I, VI, VII, y XI, (nº 4, 15, 33, 92, 109; 110, 111 y 112); ARP, 132 AQ 40, 41, 86, 128, 322, 335, 338, 722-747 y 6136-6274; ABE, Secretaría, legajos 733, 736, 740, 741, 789, 1138, 1196, 1197, 1200-1202, 1206-1218, 1224, 1259, 1260, 1262,1263 y 3820 y Cajas 706, 993, 1013-1015, 1022, 1023, 1144, 1145, 1147, 1148 y 1150, Martín (1980), Roldán (2003), Otazu (1989) y Tedde (1999).

Notas:

*Operaciones con el Tesoro Público Español, el Banco de San Fernando y de España y el Ministerio de Ultramar.

** En los años en los que los Rothschild controlaron la comercialización. Las cifras de 184849, compartidas con Baring. 